\title{
Comparison of Small- and Large-Footprint Lidar Characterization of Tropical Forest Aboveground Structure and Biomass: A Case Study From Central Gabon
}

\author{
Carlos Alberto Silva, Sassan Saatchi, Mariano Garcia, Nicolas Labrière, Carine Klauberg, António Ferraz, \\ Victoria Meyer, Kathryn J. Jeffery, Katharine Abernethy, Lee White, Kaiguang Zhao, Simon L. Lewis, \\ and Andrew T. Hudak
}

\begin{abstract}
NASA's Global Ecosystem Dynamic Investigation (GEDI) mission has been designed to measure forest structure using lidar waveforms to sample the earth's vegetation while in orbit aboard the International Space Station. In this paper, we used airborne large-footprint (LF) lidar measurements to simulate GEDI observations from which we retrieved ground elevation, vegetation height, and aboveground biomass (AGB). GEDI-like product accuracy was then assessed by comparing them to similar products derived from airborne small-footprint (SF) lidar measurements. The study focused on tropical forests and used data collected during the NASA and European Space Agency (ESA) AfriSAR ground and airborne campaigns in the Lope National Park in Central Gabon. The measurements covered a gradient of successional stages of forest development with different height, canopy density, and topography. The comparison of the two sensors shows that LF lidar waveforms and simulated waveforms from SF lidar are equivalent in their ability to estimate ground elevation (RMSE $=0.5 \mathrm{~m}$, bias $=0.29 \mathrm{~m}$ ) and maximum forest height $(\mathrm{RMSE}=2.99 \mathrm{~m}$,
\end{abstract}

Manuscript received December 5, 2017; revised March 8, 2018; accepted March 14, 2018. The work of C. A. Silva was supported in part by a Ph.D. scholarship from the National Council of Technological and Scientific Development- CNPq via the Science Without Borders Program (Process 249802/2013-9). The work of M. Garcia was supported by Marie Curie International Outgoing Fellowship within the 7th European Community Framework Programme (ForeStMap-3D Forest Structure Monitoring and Mapping, Project reference: 629376). (Corresponding author: Carlos Alberto Silva.)

C. A. Silva, S. Saatchi, A. Ferraz, and V. Meyer are with the Jet Propulsion Laboratory, California Institute of Technology, Pasadena, CA 91109 USA (e-mail: carlos_engflorestal@ outlook.com; sasan.s.saatchi@jpl.nasa.gov; ferraz.antonio.a@gmail.com; vic.meyer@gmail.com).

M. Garcia is with the Department of Geology, Geography and Environment, University of Alcalá, Madrid 28801, Spain (e-mail: mariano.garcia@uah.es).

N. Labrière is with the Laboratoire Evolution et Diversité Biologique, UMR 5174, Toulouse cedex 9 31062, France (e-mail: nicolas.labriere@ gmail.com).

C. Klauberg and A. T. Hudak are with the US Forest Service, Rocky Mountain Research Station, Moscow, ID 83843 USA (e-mail: carine_klauberg@ hotmail.com; ahudak@fs.fed.us).

K. J. Jeffery, K. Abernethly, and L. White are with the Institut de Recherche en Ecologie Tropicale, Libreville B. P. 13354, Gabon (e-mail: kjeffery@parcsgabon.ga; k.a.abernethy@stir.ac.uk; 1white@parcsgabon.ga).

K. Zhao is with the Ohio Agricultural Research and Development Center, School of Environment and Natural Resources, Ohio State University, Columbus, OH, 43210 USA (e-mail: zhao.1423@osu.edu).

S. L. Lewis is with the Department of Geography, University College London, London WC1E 6BT, U.K., and also with the School of Geography, University of Leeds, Leeds LS2 9JT, U.K. (e-mail: s.1.lewis@ucl.ac.uk).

Color versions of one or more of the figures in this paper are available online at http://ieeexplore.ieee.org.

Digital Object Identifier 10.1109/JSTARS.2018.2816962 bias $=0.24 \mathrm{~m}$ ) over the study area. The difference in the AGB estimated from both lidar instruments at the 1-ha spatial scale is small over the entire study area $\left(\mathrm{RMSE}=6.34 \mathrm{Mg} \cdot \mathrm{ha}^{-1}\right.$, bias = 11.27 $\mathrm{Mg} \cdot \mathrm{ha}^{-1}$ ) and the bias is attributed to the impact of ground slopes greater than $10-20^{\circ}$ on the $\mathrm{LF}$ lidar measurements of forest height. Our results support the ability of GEDILF lidar to measure the complex structure of humid tropical forests and provide AGB estimates comparable to SF-derived ones.

Index Terms-AfriSAR, and ice sensor (LVIS), Gabon, Global Ecosystem Dynamic Investigation (GEDI), land, lidar, tropical forest, vegetation.

\section{INTRODUCTION}

$\mathbf{N}$ ASA's Global Ecosystem Dynamics Investigation Lidar (GEDI) space mission is planned to be onboard from the International Space Station for two years beginning late 2018. The sensor will collect 25 -m diameter footprint full-waveform (FW) lidar data to help characterize vegetation structure and aboveground biomass (AGB) globally, and report on AGB dynamics across landscapes. Lidar is an active remote sensing technique that is well suited to provide high-resolution, 3-D information on vertical and horizontal forest structures and underlying topography [1]-[5]. Over the past few decades, lidar has been used to accurately retrieve ground and aboveground forest biophysical parameters, such as AGB, in temperate [6]-[9], boreal [10]-[13], and tropical forests [14]-[18]. Lidar systems for forestry applications are distinguished based on platform type (e.g., terrestrial, airborne, or spaceborne), signal recording (discrete return or $\mathrm{FW}$ ), footprint size (e.g., small, i.e., $<1 \mathrm{~m}$ or large, i.e., $10-25 \mathrm{~m}$ in diameter) and sample scanning pattern (profiling or scanning) [19], [20]. The most common lidar systems used in forestry applications have been small-footprint (SF) discrete return lidar and large-footprint (LF) FW lidar. SF lidar sensors record discrete heights at peak return of light and are typically flown on airborne platforms or operated on the ground, while LF FW lidar sensors record a continuous height distribution of surfaces illuminated by the laser pulse and are found mainly on spaceborne platforms, such as the geoscience laser altimeter system (GLAS) sensor [21]. Land, vegetation, and ice sensor 
(LVIS) is an airborne LF lidar sensor that provides coverage of large areas and can be used to simulate the characteristics of spaceborne observations such as GEDI [22]. In both LF and SF systems, canopy height metrics (i.e., maximum height, height percentiles, and canopy cover) can be derived from the recorded returned signals and may be used to retrieve aboveground forest structural properties. For example, Lefsky [23] used the GLAS data to produce a global map of forest height and Saatchi et al. [17] converted the GLAS height metrics to AGB to produce a benchmark map of carbon stocks of tropical forests across three continents. Drake et al. [14], [24] used metrics derived from LVIS to estimate a variety of forest attributes, including AGB, over a tropical forest area at the La Selva Biological Station, Costa Rica. Asner and Mascaro [25], using SF lidar, developed a series of aboveground carbon density models by calibrating the plot estimates to simple lidar metrics.

The LF and SF lidar sensors have been compared over temperate forests to study the similarity and differences in measuring the structural characteristics of forests, such as canopy height [26], [27]. However, examples of studies over tropical forests with dense and structurally complex canopy cover are scarce. Meyer et al. [28] used the two lidar datasets to examine changes in forest biomass over time, and Fricker et al. [29] used the two types of observations to develop techniques to correct for LF lidar observations over topographically complex terrain in the tropics.

Here, we aim at comparing SF and LF lidar performance in quantifying the vertical structure and biomass across a forestsavanna boundary region encompassing a natural transition from grasslands (very low AGB) to very high AGB and structurally complex ancient afrotropical forests $(>18000$ years) that include many very large trees $(>60 \mathrm{~m})$, located in central Gabon. The study focuses on variations of 3-D forest structure at the footprint and landscape scales. The lidar datasets were collected as part of a joint campaign from the NASA and the European Space Agency (ESA) which goal is to verify the performance of future spaceborne lidar (GEDI) and radar sensors (e.g., ESA's BIOMASS mission and NISAR, NASA-ISRO Synthetic Aperture Radar [30], [31]) in quantifying vertical forest structure and AGB. This paper reports on the comparison of LF and SF data over Lopé National Park (LNP) in central Gabon and examines the performance of LF simulated waveforms in detecting structure and estimating forest AGB.

\section{MATERIAL AND MethodS}

\section{A. Study Area}

The study area is located north of the LNP in central Gabon (see Fig. 1) and covers an area of approximately $50 \mathrm{~km}^{2}$. LNP is located in the western Lower Congolian semievergreen forests of central Africa [32] and is made up of dynamic, diversified vegetation types. Forest boundaries have been advancing, invading savanna grasslands under the influence of post-Pleistocene climate [32]-[34], yet anthropogenic uses of fire [35], together with the presence of elephant seed dispersal and browsing [36] have been modifying and maintaining the Lopé forest edge configuration and creating a complex system of forest types across this forest-savanna mosaic.

Annual rainfall at the study area averages $1500 \mathrm{~mm}$ (SEGC data, 1984-2016), and there are two rainy seasons and two dry seasons. The longer dry season extends from June to midSeptember, followed by the longer rainy season from midSeptember to mid-December. The shorter dry and rainy seasons are less regular and can vary in duration and intensity. The savanna and forest vegetation are on undulating terrain ranging from 230 to $470 \mathrm{~m}$ a.s.l. within slopes that can reach more than $30^{\circ}$ in the western region of the study area.

The vegetation cover in the study area can be divided into four structural types.

1) Savanna grasslands (SAV) dominated by herbaceous plants and fire-resistant woody shrubs. Two types of forest patches occur in the savanna-dominated areas: gallery forests over rocky or sandy soil along small watercourses; and isolated patches of forests or "bosquets" of anthropogenic origin, mainly found on hilltops [33], [37].

2) Young colonizing forests (YCFs) that grow as a result of fire suppression at the edge of forest-savanna boundary (YCF).

3) Okoumé (Aucoumea klaineana) dominated forests (ODF), containing mainly Okoumé and Azobe (Lophira alata) trees.

4) Marantaceae and Mature old growth forests (OGFs) found a greater distance from the current savanna edge with greater species diversity and structural complexity [33], [37].

These old forests are mainly located in the western portion of the study area at the edge of the Massif du Chaillu Pleistocene forest refuge and cover a more complex, steeply hilly terrain. Based on the SF lidar-derived canopy height model (CHM), we manually delimited four subareas across the site to represent the four major vegetation types for their variations in structure and AGB (see Fig. 1).

\section{B. Field Data Collection}

Forest inventory data were collected in field plots $(N=12$; LNL1-12) of either 1 ha (ODF, OGF, SAV; $n=9$ ) or 0.5 ha (YCF; $n=3$ ) that were designed to span a gradient of AGB from very low to high biomass values [38]-[40]. In each plot, all stems greater than $10 \mathrm{~cm}$ in diameter at breast height $(\mathrm{dbh}$, at $1.30 \mathrm{~m}$ ), or above stem irregularity and buttresses, were labeled and diameters and heights were measured. For the plots in SAV and YCF, stems $5-10 \mathrm{~cm}$ in $d b h$ were also measured as they can represent a substantial portion of AGB in such vegetation types. In all plots, trees were identified to genus level and where possible to species level. Wood density values were extracted from global datasets [41], [42]. Using diameter, height, and wood density of trees, we calculated the AGB (dry weight) of each stem using the Chave et al. [43] pantropical moist tropical forest allometric equation

$$
\operatorname{AGB}(\mathrm{kg})=0.0673 \times\left(\rho \times d b h^{2} \times h t\right)^{0.976}
$$



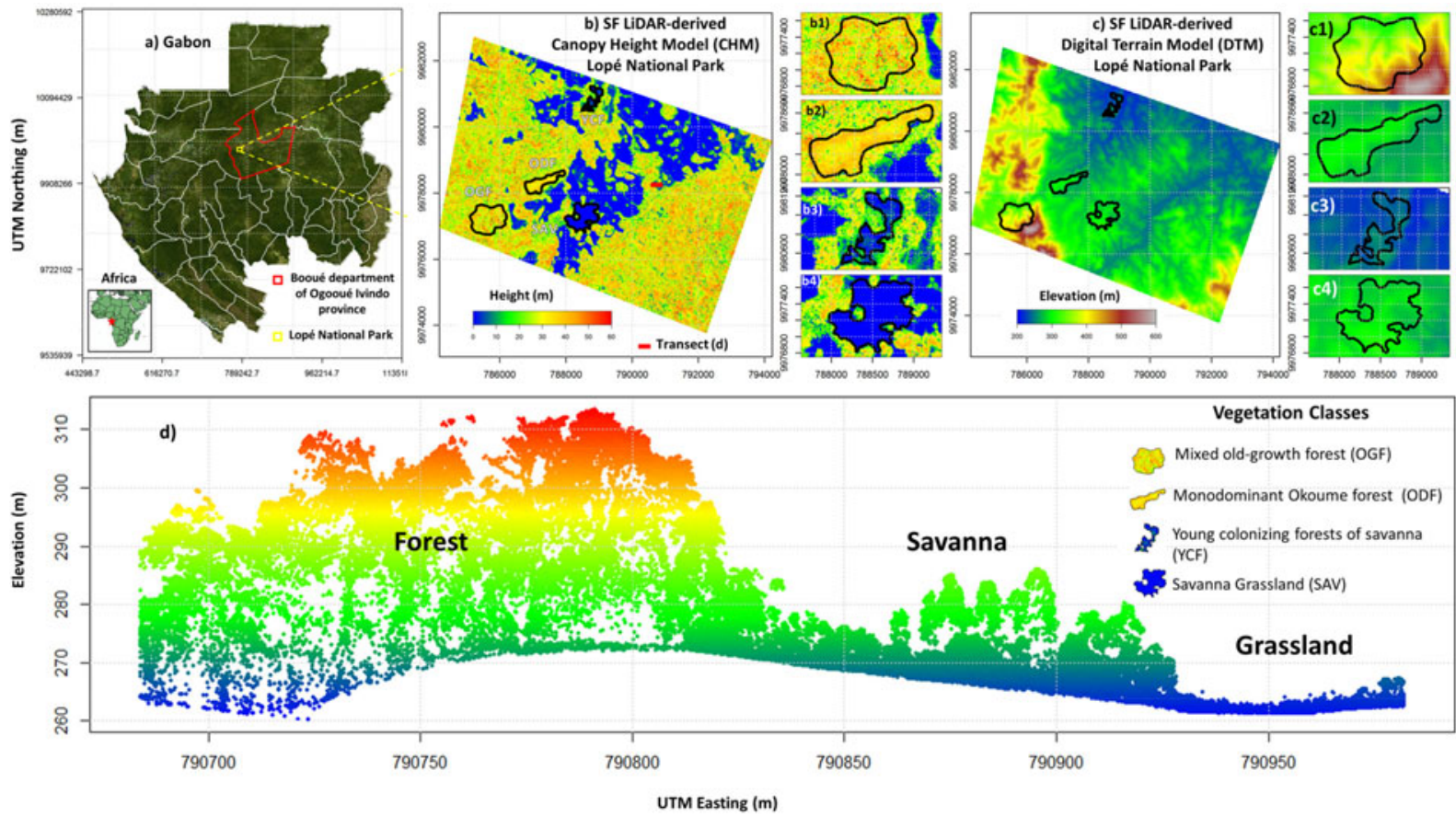

Fig. 1. (a) Study area, Gabon. (b) SF lidar-derived CHM in LNP. (c) SF-derived DTM in LNP. (D) SF-derived point cloud profile across a forest-savanna transition zone. (b1) and (c1) Mixed OGF. (b2) and (c2) Monodominant Okoumé forest (ODF). (b3) and (c3) YCFs of savanna. (b4) and (c4) Grassland savanna $(\mathrm{SAV})$.
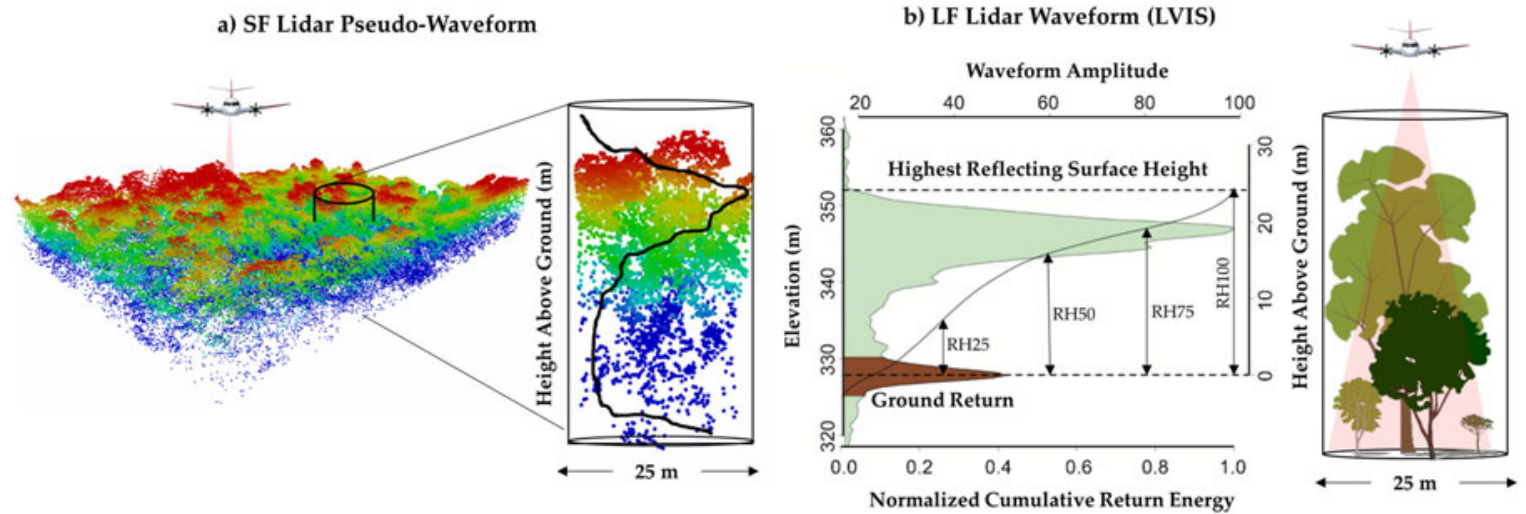

Fig. 2. (a) SF-derived pseudowaveform (vertical black line) and (b) LF-derived waveform. Canopy metrics, such as RH75, RH98, and RH100, were derived from the normalized cumulative return energy.

were $d b h$ is in $\mathrm{cm}, h t$ is in $\mathrm{m}$, and $\rho$ is the wood density in $\mathrm{g} \cdot \mathrm{cm}^{-3}$. The total AGB at plot level was then obtained by summing individual stem biomass estimates and converting it to $\mathrm{Mg} \cdot \mathrm{ha}^{-1}$.

\section{Lidar Data and Processing}

1) SF Lidar: The SF DR lidar data were collected using a Riegl VQ480U sensor mounted on a helicopter model EC 135 in July 2015 with a variable point density and footprint diameter of $\sim 10 \mathrm{~cm}$. Data were preprocessed to remove artifacts due to helicopter motion. This provided a more uniform point density of $\sim 10$ points $\cdot \mathrm{m}^{-2}$ for vegetation characterization. In this study, digital terrain model (DTM), slope, CHM, and canopy metrics derived from simulated pseudowaveforms were computed based on the following steps: first, ground returns were classified using the progressive triangulated irregular network densification algorithm [44], and a 1-m DTM was created. Slope (\%) maps were derived from the DTM. Second, normalized height (i.e., the height above ground) was obtained for each point of the point cloud by subtracting ground elevation (obtained from the DTM) from the raw point elevation value, and the 1-m CHM was then computed using the highest points. Finally, within each LVIS footprint, the SF lidar point cloud was clipped and pseudo-waveforms were simulated by convoluting the returns within each footprint [see Fig. 2(a)] [27]

$$
\begin{aligned}
& \mathrm{WV}(z)=\left[\sum_{i \in U} I_{i} \cdot w_{h}\left(x_{i}, y_{i}\right)\right] * w_{v}\left(\frac{2 \cdot z}{c}\right) \\
& \mathrm{U}=\left\{i: \sqrt{\left(x_{i}-x_{0}\right)^{2}+\left(y_{i}-y_{0}\right)^{2}} \leq r \text { and }\left|z_{i}-z\right| \leq \frac{\Delta h}{2}\right\}
\end{aligned}
$$


where $\left(x_{i}, y_{i}, z_{i}\right)$ are the coordinates of each discrete return, $\left(x_{0}, y_{0}\right)$ refer to the coordinates of the footprint center, $r$ is the footprint radius (i.e., defined as half of the $\mathrm{e}^{-2}$ of the maximum rather than half of the full-width at half-maximum), $\Delta h$ is the sensor discretization interval ( $15 \mathrm{~cm}$ for LVIS), $U$ denotes the set of those SF lidar returns within the SF footprint $(25 \mathrm{~m}$ in diameter), $I_{i}$ is the intensity of each return, and ${ }^{*}$ denotes the convolution operator. The Gaussian distribution of energy both along and across the laser beam was approximated by $w_{v}$ and $w_{h}$

$$
\begin{aligned}
w_{h}(x, y) & =\exp \left[-2 \frac{\left(x_{i}-x_{0}\right)^{2}+\left(y_{i}-y_{0}\right)^{2}}{r^{2}}\right] \\
w_{v}(t) & =\exp \left[-2 \frac{\left(t-t_{0}\right)}{\sigma_{t}^{2}}\right]
\end{aligned}
$$

where $t_{0}$ is a reference time corresponding to the peak of an emitted pulse, and $\sigma_{t}$ is the interval from $t_{0}$ to the time at which the intensity along the beam drops to $\mathrm{e}^{-2}$ of the maximum. The pulse duration was set to $10 \mathrm{~ns}$ [40].

After simulating the LVIS waveforms, canopy relative height metrics (SF RH) were calculated based on the cumulative waveform energy (i.e., 10\%, 25\%, 50\%, 75\%, 98\%, and 100\%; RH10, RH25, R50, RH75, RH98, and RH100). The SF data processing was done using FUSION/LDV [38], Lastools [39], R [43], and MATLAB [44] softwares.

2) LF Lidar: The LF FW lidar data were acquired in February 2016 using the LVIS sensor, developed and operated by the Laser Remote Sensing Laboratory at NASA's Goddard Space Flight. In this study, LVIS was mounted on the NASA Langley B200 aircraft and flown at $\sim 7315 \mathrm{~m}$ with a footprint diameter of $25 \mathrm{~m}$ and nominal spacing of $\sim 10 \mathrm{~m}$ both along and across track. LVIS footprints were geolocated to the global reference ellipsoid WGS 84, using a combination of GPS and inertial navigation system (INS) information [45], [50]. Our preliminary analyses indicate that LVIS data geolocation match very well with that of SF DR lidar data and that sensor comparison did not require any further geolocation correction.

LVIS is a FW digitizing system that records the vertical distribution of nadir-intercepted surfaces at $15 \mathrm{~cm}$ vertical resolution [51] using the return energy of Gaussian-shaped optical pulses at a wavelength of $1064 \mathrm{~nm}$ [51] [see Fig. 2(b)]. Essentially, the amplitude of a LVIS waveform signal is proportional to the energy reflected from canopy-intercepted surfaces and the ground [52]. For each LVIS waveform, ground elevation (ZG) was defined as the center of the lowest mode in the waveform greater than mean signal noise [52], [53], and height metrics relative to ground elevation (LF RH) were calculated based on the normalized cumulative return energy [52], [54]. In general, RH100 is considered a noisy metric because it is associated with the first return and depends strongly on the signal-to-noise ratio (SNR) setup in LF lidar measurements. In comparing LF to SF lidar measurements, RH98 (heights at 98 percentiles of energy) was found to be more precise. Other metrics such as canopy cover can be computed based on the LVIS waveform. However, for this study, we only used ZG, RH75, and RH98 (representing ground elevation, canopy height at $75 \%$ and $98 \%$ of the laser return energy, respectively) for comparison purposes and AGB modeling.

\section{Comparison of SF Versus LF Lidar-Derived Metrics for Ground and Forest Structure Attribute Retrieval}

1) Ground and Canopy Height Comparison: We compared ground elevation (ZG) and top-of-canopy height (RH98) retrieved from SF and LF lidar at different spatial levels (LVIS footprint and grid) over the subareas selected to represent the gradient of successional stages of vegetation found in the study area (see Section II-A). For each metric, the comparison was performed using the two-sided Wilcoxon-Mann-Whitney ranksum and equivalence tests [56], [57], at a significance level of 0.05 in $\mathrm{R}$ [43]. At the footprint level, SF ZG was computed as the mean of ground elevation from DTM within the footprint area. At the grid level, SF and LF lidar-derived ground elevation and top-of-canopy height were averaged at 25, 50, and $100 \mathrm{~m}$ spatial resolutions leading to mean ZG (SF_ZG_MEAN and LF_ZG_MEAN) and mean RH98 (SF_RH98_MEAN and LF_RH98_MEAN). Different grid cell resolutions were tested to quantify 1) how well the two observations characterize the landscape variations of aboveground forest structure at different scales; and 2) how differences between the two systems scale with grid cell resolution. This approach will also allow us to understand how many footprints from LF sensors are required to capture landscape variability in forest structure and biomass. This, in turn, will provide useful information regarding GEDI projected sampling densities to accurately retrieve canopy height and biomass over complex tropical landscapes.

2) $A G B$ : We developed models between ground-based AGB and either SF or LF height lidar metrics at the plot level using the nonlinear least squares function in R [48]. For each sample plot, the mean of SF lidar-derived CHM (MCH) and LF lidarderived RH75 were computed (SF_MCH; LF_RH75_MEAN) and used as independent variables for modeling AGB. Both metrics have been successfully used to estimate AGB in other forest ecosystems [25], [55]. In a study comprising 14 distinct tropical ecoregions, Asner and Mascaro [25] reported that lidar estimates of AGB using MCH compared well (within 10-15\% error) with ground-estimated AGB at 1-ha scale. As for LF lidar, Sun et al. [55] found RH75 to be the best metric to model AGB in mixed hardwood and softwood forests. While RH metrics other than RH75 have been used in other studies, higher percentile metrics (e.g., RH99 or RH100) are often affected by noise, and lower percentile metrics (e.g., RH50) tend to be affected by distorted waveforms or lower density point clouds in the presence of complex terrains.

We adopted a widely used power-law model to express the relationship between the corresponding height metrics and AGB [25]. The model predictions were evaluated in terms of coefficient of determination $\left(R^{2}\right)$, root mean square error (RMSE), and bias in $\mathrm{Mg} \cdot \mathrm{ha}^{-1}$ :

$$
\mathrm{AGB}=\beta_{0} \cdot{\overline{H_{L}}}^{\beta_{1}}+\varepsilon
$$


with $\varepsilon \sim N\left(0, \sigma^{2}\right)$

$$
\begin{aligned}
\text { RMSE } & =\sqrt{\frac{\sum_{i=1}^{n}\left(\hat{y}_{i}-y_{i}\right)^{2}}{n}} \\
\text { Bias } & =\frac{1}{n} \sum_{i=1}^{n}\left(\hat{y}_{i}-y_{i}\right)
\end{aligned}
$$

where $\mathrm{AGB}$ is the aboveground biomass in ${\mathrm{Mg} \cdot h a^{-1}, \overline{H_{L}}}$ is the lidar-derived mean forest canopy height metric (either SF_MCH_MEAN, or LF_RH75_MEAN), $n$ is the number of plots, $y_{i}$ is the observed value for plot $i$, and $\hat{y}_{i}$ is the predicted value for plot $i$. We also calculated relative RMSE and biases by dividing the respective absolute values [cf. (7) and (8)] by the mean of predictions.

For validation purposes, the AGB models were embedded in a bootstrap procedure with 100 iterations. In each bootstrap iteration, we drew 12 times with replacement from the 12 available samples. In this procedure, on average $44 \%$ of the total number of samples ( $\sim 5$ samples) are not drawn. These samples were subsequently used as holdout samples for independent validation. In each bootstrap iteration, Adj. $R^{2}$ and relative and absolute RMSE and biases were computed based on the linear relationship between observed and predicted AGB using the holdout samples. Wilcoxon-Mann-Whitney rank-sum and equivalence tests were also used to assess if the mean of predicted AGB from the 100 iterations and the observed AGB mean differed at a significance level of 5\%.

The height metrics SF_MCH and LF_RH75_MEAN were computed for the entire site at a spatial resolution of $100 \mathrm{~m}$, and the fitted models were applied to map AGB at landscape level. SF- and LF-derived AGB estimates were then compared at landscape level and summarized for the four vegetation types described in Section II-A.

The uncertainty analysis was performed at the landscape level, on the SF and LF AGB-derived maps for the entire site and for each subarea (see Section II-A). The total uncertainty was computed by integrating the pixel level errors over the regions of interest (ROI) and accounting for spatial autocorrelation of errors as follows [58]-[60]:

$$
\begin{aligned}
\sigma_{\mathrm{AGB}}^{2}(\mathrm{ROI}) & =\frac{1}{m^{2}} \sum_{i=1}^{m} \sum_{j=1}^{m} \operatorname{cov}\left(\sigma_{i}, \sigma_{j}\right) \\
& =\frac{1}{m^{2}}\left(\sum_{i=1}^{m} \sigma_{i}^{2}+2 \sum_{i=1}^{m} \sum_{i<j}^{m} \rho(d) \sigma_{i} \sigma_{j}\right)
\end{aligned}
$$

where $\sigma_{\mathrm{AGB}}^{2}$ is the variance of the estimator for the mean AGB for the ROI (i.e., the entire study area or subareas), $m$ is the number of pixels, cov represents the covariance of pixel errors, $\sigma_{i}$ is the estimated standard error (SE) of AGB at the $i$ th pixel, and $\rho(d)$ is the spatial correlation function based on an exponential semivariogram model depending on the distance $d$ between pixels $i$ and $j$ within the ROI [58]. The square root of the variance $\left(\sigma_{\mathrm{AGB}}^{2}\right)$ is the SE, which is reported as the uncertainty [58]-[60] in our analysis.

\section{E. Impacts of Sample Size on AGB Estimation}

The GEDI instrument will operate with a footprint of $25 \mathrm{~m}$ similar to LVIS LF, but each footprint will be separated by $60 \mathrm{~m}$ along track and $500 \mathrm{~m}$ across track between each of 10 tracks. In order to evaluate the performance of GEDI for modeling AGB in tropical forests, we examine the number of footprints required to have a relatively unbiased estimate of AGB at 1 ha. By subsampling the LVIS LF footprints, we assessed the impacts of LF sample size on AGB modeling at the plot level. The footprint density from LVIS varied at different locations in the study area because of the spatial variation of overlapping flight lines during the campaign. On average, $72 \pm 23$ (sd) footprints were registered over each field plot. We randomly downscaled the number of footprint to $10,5,3$, and 1 for each plot, and LF_RH75_MEAN was then computed for AGB modeling. For the simulation where only one footprint shot was kept, we used the LF RH75 value for AGB modeling. Simulations were repeated 100 times and distribution histograms of $R^{2}$, RMSE, bias and model parameters were computed for each subsampling case. Thus, we were able to assess how well one GEDI footprint randomly located within a 1-ha plot will be able to retrieve plot AGB.

\section{RESUlTS AND DISCUSSION}

\section{A. Comparison of SF and LF Lidar-Derived Ground Elevation and Canopy Height at Footprint Level}

The SF and LF lidar-derived ground elevation data are strongly correlated (Adj. $\mathrm{R}^{2}=0.99$; Fig. 3). The mean difference in ground elevation across all vegetation types is $1.01 \pm$ $0.99 \mathrm{~m}$ (n.s.; $p$-value $=0.78$; Wilcoxon-Mann-Whitney ranksum test). Difference in ground elevation between SF and LF is the highest in the most structurally complex OGF subarea $(\mathrm{RMSE}=2.46 \mathrm{~m}, \mathrm{rRMSE}=0.63 \%) . \mathrm{LF}$ and SF lidarderived RH98 over the study area show significant differences at footprint level for ODF, YCF, and SAV (mean RMSE = $2.06 \pm 1.20 \mathrm{~m}$, mean bias $=0.81 \pm 0.71 \mathrm{~m})$. Even though differences in RH98 can be higher than $10 \mathrm{~m}$ (RMSE $\sim 4 \mathrm{~m}$ ) in OGF, it is not significant for the four subregions combined and does not show a bias across the height range (bias $=0.47 \mathrm{~m}$ ). Yet, based on equivalence tests, SF and LF lidar-derived ground elevation (ZG) and top-of-canopy height (RH98) at footprint level are found equivalent across all vegetation types.

Although we did not find significant differences between the two measurements when analyzing all footprints within the sub regions, there were some large differences between the two datasets at individual footprint level (see Fig. 3). These differences reached up to 10 and $20 \mathrm{~m}$ for ground elevation and top-of-canopy height detection, respectively. Errors remained random though across footprints. By analyzing individual footprints with large differences in ZG and RH98, we found several potential sources of uncertainty in individual measurements when comparing the two datasets.

1) Ground topography is a significant source of error in LF lidar quantification of ZG and RH98. Slope (both its variations within a LF lidar footprint and its orientation against 

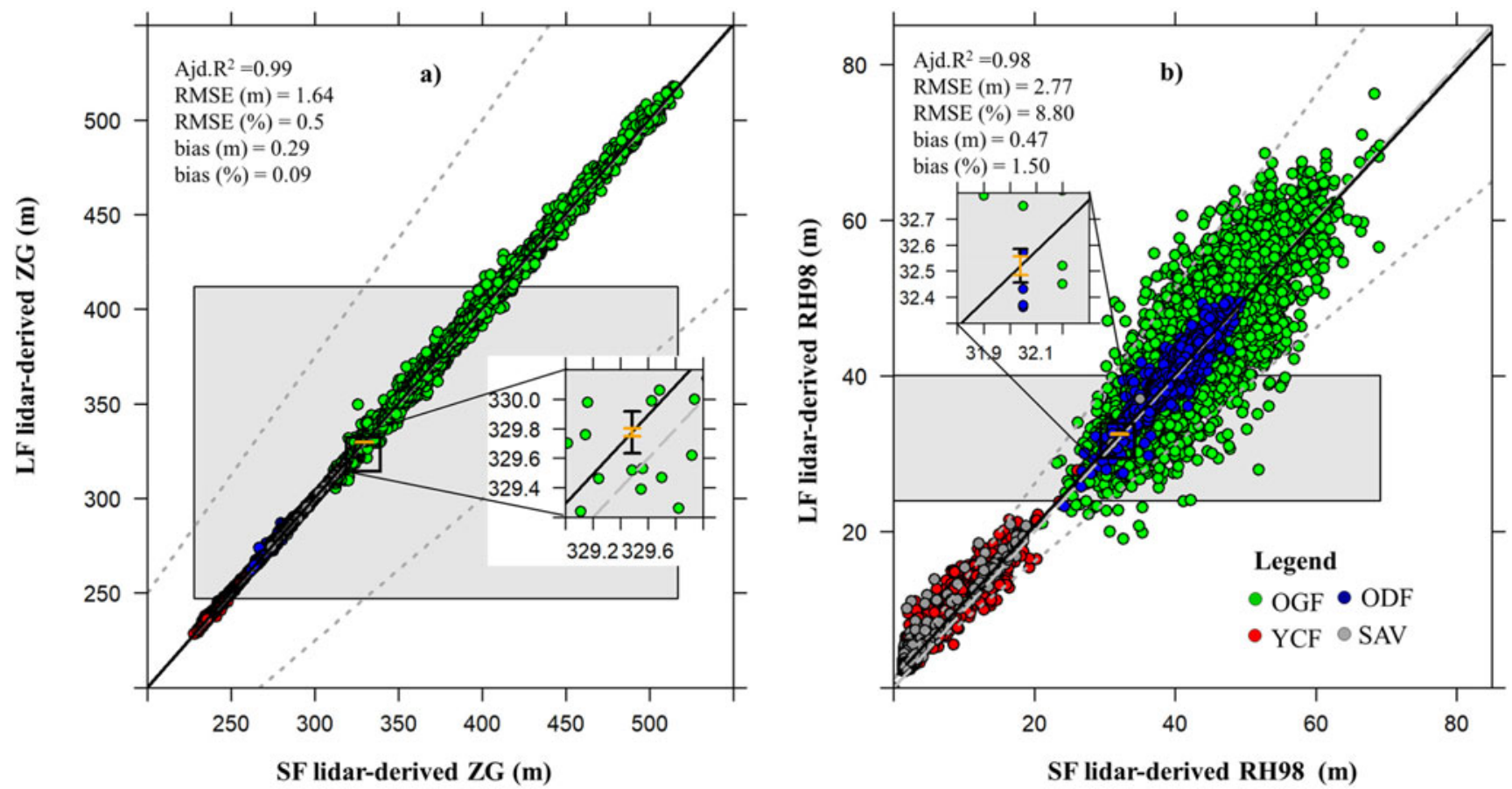

Fig. 3. (a) Comparison of SF and LF lidar-derived ground elevation and (b) top-of-canopy height at footprint level using the equivalence test. Mixed OGF. Monodominant Okoumé forest (ODF). YCFs of savanna. Grassland savanna (SAV). The equivalence plot design presented herein is an adaptation of the original equivalence plots presented by Robinson [57], examples are shown in [61]-[64]. The gray polygon represents the $\pm 25 \%$ region of equivalence for the intercept, and the orange vertical bar represents a 95\% confidence interval for the intercept. The LF ZG and RH98 are equivalent to SF ZG and RH98 on both intercept and slope as long as the orange bar remain completely within the gray polygon. If the gray polygon is lower than the orange vertical bar, the measurements would be negatively biased; and if it is higher than the orange vertical bar, the LF ZG and RH98 are positively biased. Moreover, the gray-dashed line represents the $\pm 25 \%$ region of equivalence for the slope, the fit line is within the dotted lines, and the black vertical bar is within the gray rectangle, indicating that the pairwise measurements are equivalent. An orange and black vertical bar that are wider than the region outlined by the gray-dashed lines indicates high variance for SF measurements. The white dots are the pairwise measurements, and the solid line is a best-fit linear model for the pairwise measurements. The light gray-dashed line represented the 1:1 relationship.

lidar observation) has been shown to induce errors in ground elevation retrieval [50], [65]-[67]. In our study site, particularly under dense canopy, the individual LF lidar ZG values may have large errors (see Fig. 4). However, similar errors may also appear in SF retrieval of ZG. Depending on pulse density and observation geometry (i.e., viewing angles), there may be no ground-classified points over slopes and the interpolated DTM may miss microtopographical variations across the landscape. If the individual LF lidar and the SF lidar pseudowaveforms footprint fall over complex terrains with dense forest cover, the errors from both measurements can introduce large differences in the footprint level ZG values. In most studies, the difference in ZG is often attributed to uncertainties associated with LF measurements [27]. However, in dense tropical forests, SF measurements may also have errors in detecting ZG depending on the pulse density and ground interpolation method [18].

2) Canopy structure might also introduce uncertainty when calculating canopy height from LF lidar. In a study carried out in Sierra National Forest, USA, Hyde et al. [51] reported that differences between field and LVIS measurements of canopy height and biomass were mainly attributable to the spatial configuration of canopy elements and were less sensitive to topography, crown shape, or canopy cover. For instance, in our study, we identified that most of the large differences in RH98 were found in footprints located at higher slopes and across the transition from savanna to forest. In this case, taller trees located at the edges were detected by the SF lidar, but not detected from the LF lidar because of the low laser intensity at the edge of the footprint. In LF systems, Gaussian waveforms drop off in power across the footprint, resulting in a lack of sensitivity to canopy material progressively toward the edges of the footprint [51]. Fig. 4 shows examples of footprints and geometry of canopy within the footprint from SF simulations over three different terrains and conditions where RH98 derived from LF lidar may be very similar [see Fig. 4(a1)-(d1)], larger [see Fig. 4(a2)(d2)], or smaller [see Fig. 4(a3)-(d3)] than that derived from SF lidar. In most comparisons between LF and SF data, it is considered that SF lidar-derived RH98 must be higher than LF lidar. SF measurements may have a return from a small leaf on the top of the canopy but LF requires enough leaves on the top of the canopy to have a significant return higher than SNR. However, when simulating the LF canopy height metrics from SF measurements, the difference may be due both under and overestimation.

3) Simulation of LF data from SF measurements may also be a source of error in comparing RH98 at individual 

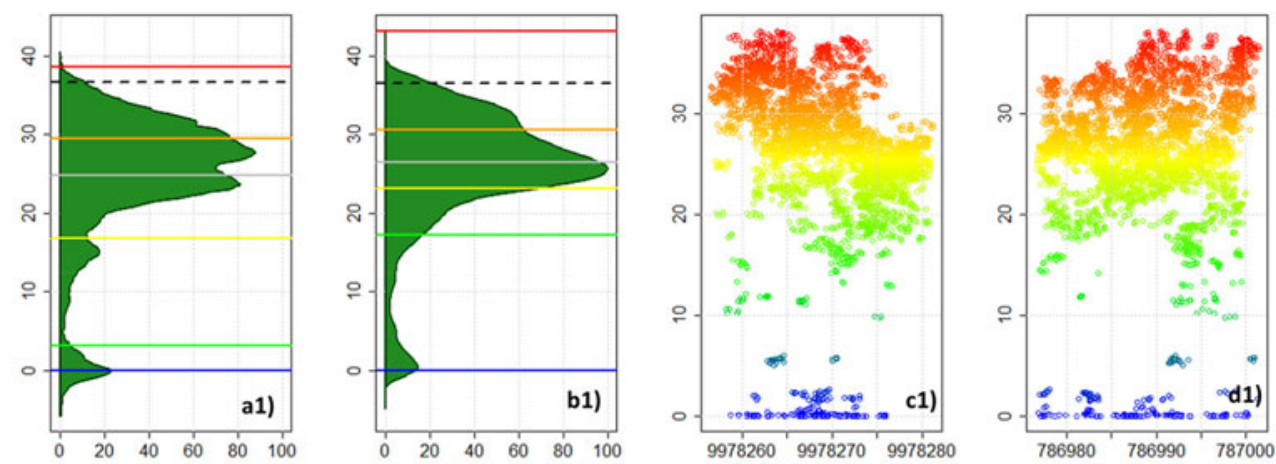

e1)
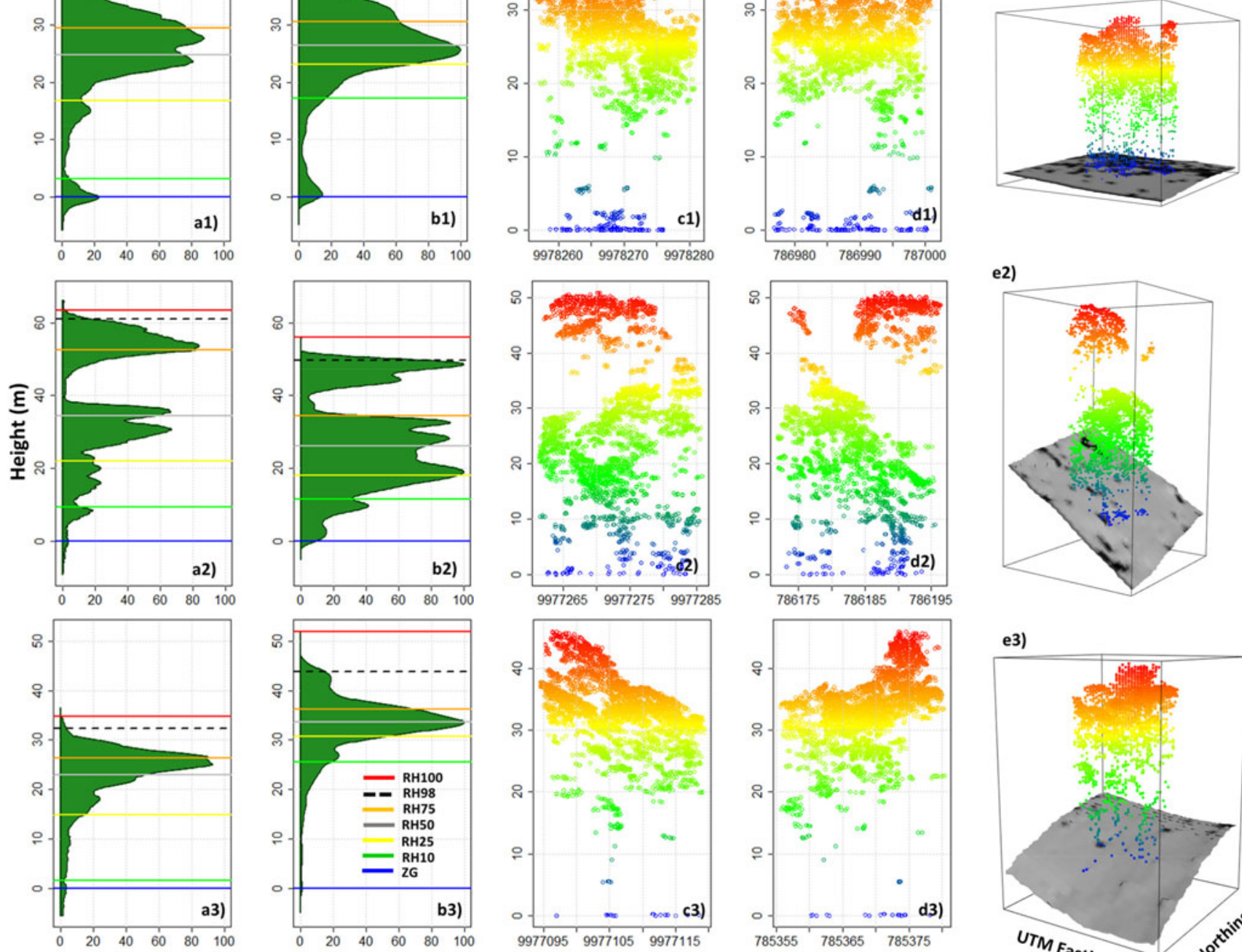

Waveform Amplitude

UTM Northing (m)

UTM Easting (m)

e3)

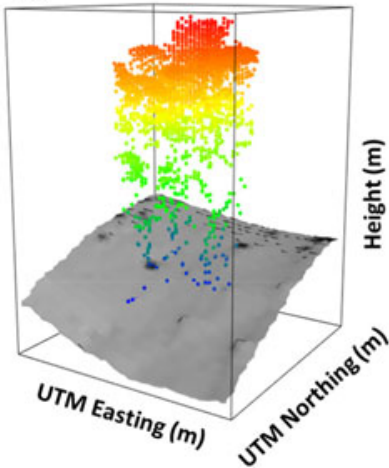

Fig. 4. Comparison of LF and SF waveforms. (a1)-(a3) LF and (b1)-(b3) SF waveforms at footprint level. SF point cloud in (c1)-(c3) and (d1)-(d3) 2-D and in (e1)-(e3) 3-D. (a1) and (d1) Footprint with a difference in RH98 of 0.12 m (UTM E: 786989 N: 9978269). (a2) and (d2) With a difference in RH98 of 11.32 m (UTM E: 786184 N: 9977274). (a3) and (d3) Footprint with difference in RH98 of -11.48 m (UTM E: 785368 N: 9977107). The SF-derived pseudowaveform is smoothed for better display herein.

footprint level. Our result in Fig. 3(b) shows that this error can be large and without any preference or bias toward one lidar measurement type. Simulation of LF footprint waveforms from SF measurements may include errors associated with the geometry of measurements, the form of Gaussian weighting and small geolocation error that may partially include or exclude large trees around the footprint edges.

\section{B. Comparison of SF- and LF-Derived Ground Elevation and Canopy Height at Grid Levels}

SF_ZG_MEAN and LF_ZG_MEAN were strongly correlated $\left(\right.$ AdjR $\left.^{2}{ }^{2}=0.99\right)$ with RMSE $\leq 1.02 \mathrm{~m}(0.31 \%)$ and bias $\leq 0.31 \mathrm{~m}(0.09 \%)$ whatever the spatial resolution (see Fig. 5). Moreover, LF_RH98_MEAN and SF_RH98_MEAN were also strongly correlated at all spatial scales with RMSE $\leq 1.66 \mathrm{~m}$ $(6.14 \%)$ and bias $\leq 0.62 \mathrm{~m}(2.94 \%)$. The difference between SF and LF measurement of ZG_MEAN and RH98_MEAN decreased $\sim 32 \%$ in relative RMSE from 25 to 100 m resolutions. Equivalence tests showed that SF and LF for both ZG_MEAN and RH98_MEAN were equivalent across all spatial resolutions, but Wilcoxon-Mann-Whitney rank-sum tests showed significant differences in SF and LF lidar-derived RH98 at spatial resolutions of 25 and $50 \mathrm{~m}$ [see Fig. 5(a2) and (b2)].

LF predominantly overestimated ground elevation when compared with SF lidar, yet differences exceeding $2 \mathrm{~m}$ were only found in the OGF area (see Fig. 6). For RH98_MEAN, we observed both under and overestimation, and differences $\geq 1.5 \mathrm{~m}$ were also found in the OGF area. As the grid cell size of the maps increased from 25 to $100 \mathrm{~m}$, the spread of the differences of SF and LF also decreased as shown by the distribution of 

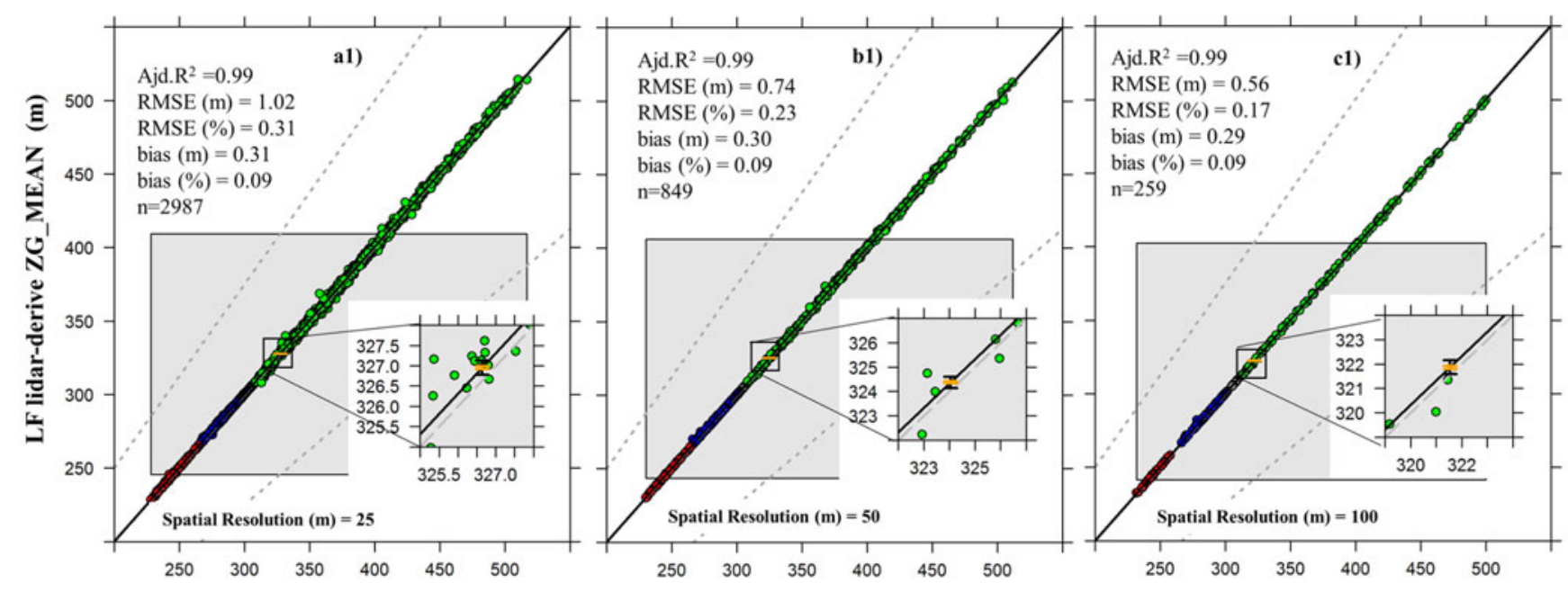

SF lidar-derive ZG_MEAN (m)
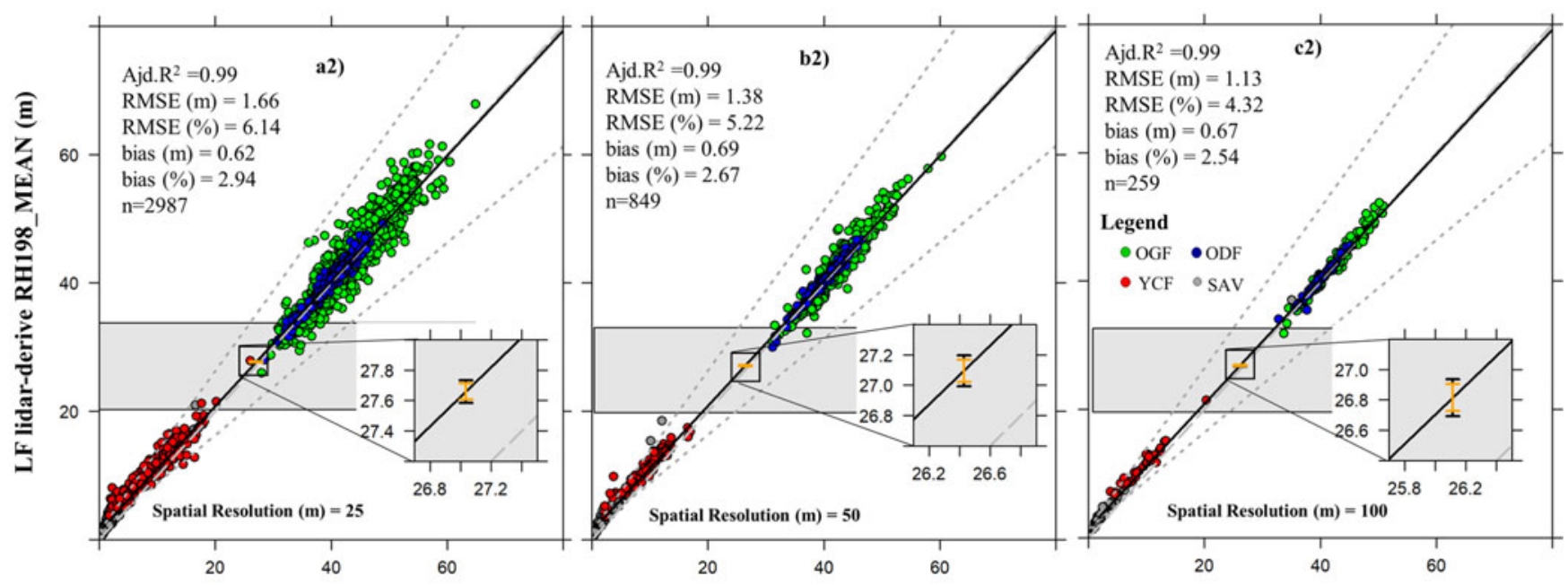

SF lidar-derive RH98_MEAN (m)

Fig. 5. Equivalence test of (a1) and (c1) mean ground elevation (ZG_MEAN) and (a2) and (c2) mean canopy height (RH98_MEAN) at spatial resolution of (a1) and (a2) 25, (b1) and (b2) 50, and (c1) and (c2) $100 \mathrm{~m}$. Mixed OGF. Monodominant Okoumé forest (ODF). YCFs of savanna. Grassland savanna (SAV).

their differences [see Fig. 6(a-g1.2-3.2)]. The comparison of the two sensors at different grid cells revealed the importance of aggregated measurements to capture the landscape variations of the forest structure. By averaging several LF lidar footprints within a 1-ha area, random errors between the two measurements were reduced significantly, allowing the measurements to converge in representing the landscape characteristics of the forests in the study area. Comparison of Figs. 3 and 5 readily shows the impact of LF footprint aggregation even with $25-\mathrm{m}$ grid cells.

The comparison of LF- and SF-derived ground and canopy height measurements (see Figs. 5 and 6) might have been affected to an unknown degree due to the time lag of seven months between the two lidar datasets. However, this effect is subtle owing to the longer time spans that are needed for vertical structure of tropical forest to be changed. Moreover, this is presumably more influential on the RH98 metric on SAV and YCF than on OGF and ODF due to substantially faster growth rate of those subregions. The only potential impact on OGF and ODF layers would be due to natural tree falls or branch snapping between the two dates. Yet, these events are not widespread and although they may impact some LF lidar footprints (acquired after SF), the impact on the overall statistics should be small.

\section{Comparison of SF and LF AGB Models}

1) Biomass Model Performance: SF_MCH and LF_RH75 _MEAN were significantly correlated with AGB at plot levels (see Table I). AGB was overestimated in both SF (Bias: $1.24 \mathrm{Mg} \cdot \mathrm{ha}^{-1}$ ) and LF (bias: $2.47 \mathrm{Mg} \cdot \mathrm{ha}^{-1}$ ) models after bootstrapping the performance with 100 repetitions. However, the Wilcoxon-Mann-Whitney rank-sum and equivalent tests showed that SF and LF AGB estimates at plot level are both equivalent to the ground-estimated AGB ( $p$ value $\geq 0.93$ ). According to these tests, the mean AGB estimates from the bootstrapping procedure are equivalent with ground-estimated AGB 

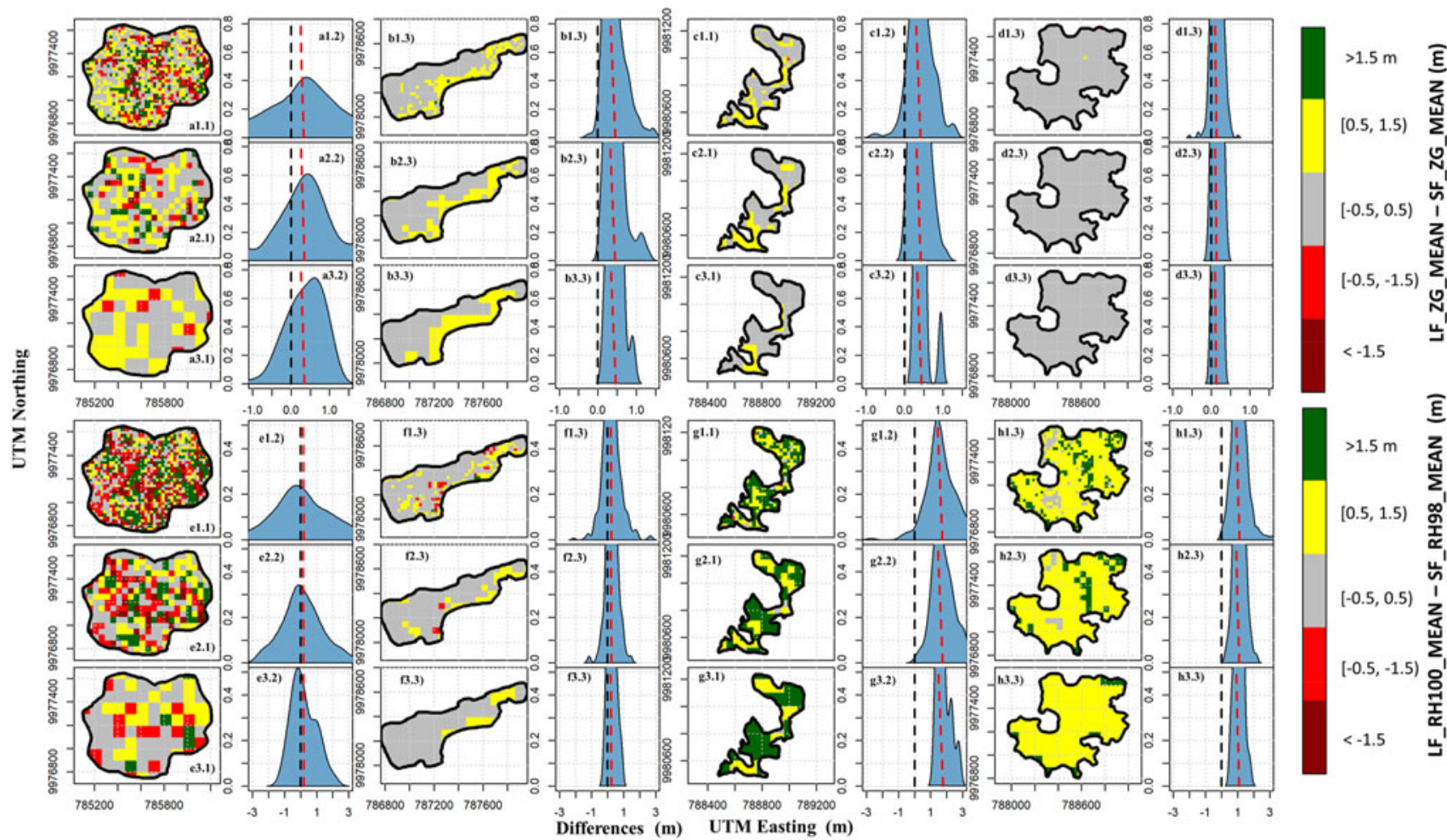

Fig. 6. Spatial distribution of differences between SF and LF lidar-derived ground elevation (ZG_MEAN) and top-of-canopy height (RH98_MEAN) for different vegetation types and spatial resolutions. We focused on four vegetation types: (a1.1)-(a3.2) and (e1.1)-(e3.2) mixed OGF; (b1.1)-(b3.2) and (f1.1)-(f3.2) monodominant Okoumé forest (ODF), (c1.1)-(c3.2) and (g1.1)-(g3.2) YCFs of savanna; and (d1.1)-(d3.2) and (h1.1)-(h3.2) grassland savanna (SAV). Three spatial resolutions were considered: (a1.1) and (h1.1) $25 \mathrm{~m}$, (a2.1) and (h2.1) $50 \mathrm{~m}$, and (a3.1) and (h3.1) $100 \mathrm{~m}$. The blue graphs represent the distribution of differences between SF and LF lidar-derived ZG_MEAN and RH98_MEAN. The black- and red-dashed lines represent the 0 and mean of difference distribution, respectively.

TABLE I

NONLINEAR POWER-LAW AGB MOdELS $(n=12)$

\begin{tabular}{|c|c|c|c|c|c|c|}
\hline \multirow[t]{2}{*}{ Lidar } & \multirow[t]{2}{*}{ Models } & \multirow[t]{2}{*}{$R^{2}$} & \multicolumn{2}{|c|}{ RMSE } & \multicolumn{2}{|c|}{ Bias } \\
\hline & & & $\mathrm{Mg} \cdot \mathrm{ha}^{-1}$ & $\%$ & $\mathrm{Mg} \cdot \mathrm{ha}^{-1}$ & $\%$ \\
\hline SF & $\mathrm{AGB}_{\mathrm{SF}}=7.56 \times \mathrm{SF}_{-} \mathrm{MCH}^{1.06}$ & 0.94 & 34.28 & 17.32 & 1.24 & 0.63 \\
\hline LF & $\mathrm{AGB}_{\mathrm{LF}}=6.40 \times$ LF_RH75_MEAN ${ }^{1.11}$ & 0.93 & 37.28 & 18.72 & 2.47 & 1.24 \\
\hline
\end{tabular}

( $p$ value $\geq 0.89$ ) as well [see Fig. 7(a)]. SF and LF AGB estimates at plot level, both from the model and bootstrapping procedure, are also equivalent ( $p$ value $\geq 0.88$ ) [see Fig. 7(b)].

At the 1-ha scale, the number of plots was limited to 12 , and although this captures variation in biomass across the forest types, it may not be enough to develop a more robust crossvalidation test of model performance. However, the accuracies, both for training and validation models, presented herein were similar to those reported in previous studies [8], [14], [28]. This analysis can be done at different spatial scales to allow more GEDI footprints over larger landscapes, but requires either large ground plots or a more complex error propagation if compared with SF lidar-derived AGB. A more complex sampling approach to exactly mimic the GEDI samples over the landscape was beyond the scope of this study and hence is not considered in this paper.
2) AGB Maps: Landscape-wide AGB estimates based on models from Table I were mapped at 1-ha (i.e., $100 \mathrm{~m} \times 100 \mathrm{~m}$ ) grid cell resolution (see Fig. 8). The equivalence and WilcoxonMann-Whitney rank-sum tests showed that LF and SF lidarderived AGB maps were equivalent at landscape level ( $p$ value $>0.05$ ), with LF lidar-derived AGB predictions showing a RMSE and bias of $6.34 \mathrm{Mg} \cdot \mathrm{ha}^{-1}(2.84 \%)$ and $11.27 \mathrm{Mg} \cdot \mathrm{ha}^{-1}$ (5.05\%), respectively, compared to SF ones. LF lidar-derived AGB was larger than SF-derived AGB across OGF [see Fig. 8(b)], that were predominantly distributed across areas with slopes larger than 10 degrees [see Fig. 8(c)]. The uncertainty of AGB estimates at landscape level for the entire study area and for the four ROI are derived by taking into account the pixel base model errors from the bootstrapping approach and the spatial correlation of errors as presented in Table II. 

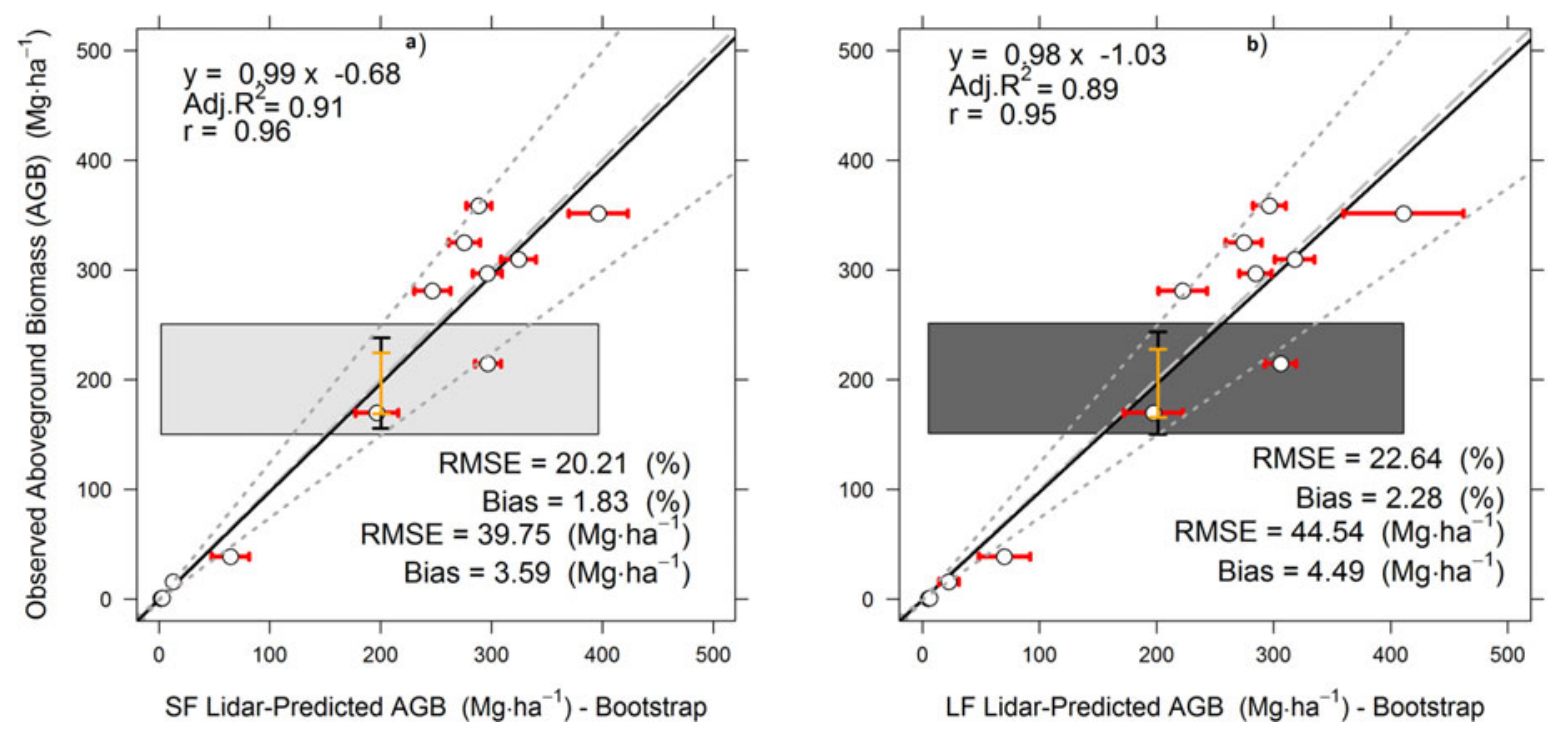

Fig. 7. Equivalence plots of the observed and predicted AGB $\left(\mathrm{Mg}_{\mathrm{n}} \mathrm{ha}^{-1}\right)$ obtained from the 100 bootstrapped model runs using (a) SF_MCH and (b) LF_RH75MEAN $(N=12)$. The white dots are the pairwise measurements, and the solid line is a best-fit linear model for the pairwise measurements. The horizontal red bar is the standard deviation of AGB estimates from the bootstrapping procedure. The light gray-dashed line represented the relationship 1:1. $N=12$.

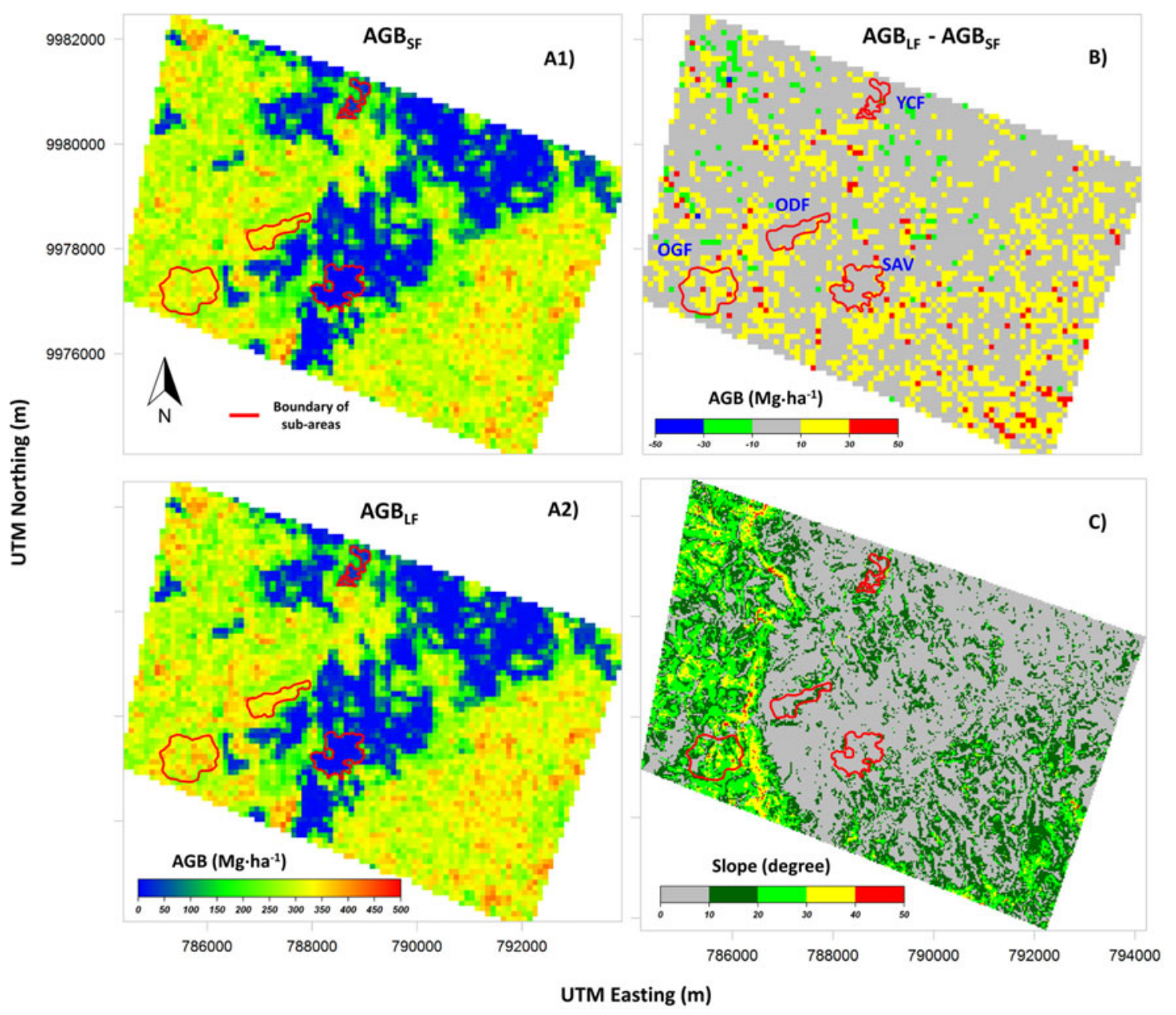

Fig. 8. (a1) SF and (b2) LF lidar-derived AGB estimates at the landscape level. (b) Difference in AGB estimates between SF and LF lidar. (c) Slope (degree) map. Mixed OGF. Monodominant Okoumé forest (ODF). YCFs of savanna. Grassland savanna (SAV). 
TABLE II

SUMMARY OF SF AND LF LIDAR-DERIVED AGB ESTIMATES AND UNCERTAINTIES AT LANDSCAPE LEVEL FOR THE ENTIRE STUDY AREA AND ROI

\begin{tabular}{lcccccc}
\hline \hline \multirow{2}{*}{ ROI } & \multirow{2}{*}{ Area (ha) } & \multicolumn{2}{c}{ SF lidar } & & \multicolumn{2}{c}{ LF lidar } \\
\cline { 3 - 4 } \cline { 6 - 7 } & & Mean $\pm \mathrm{Std}\left(\mathrm{Mg} \cdot \mathrm{ha}^{-1}\right)$ & $\mathrm{SE}\left(\mathrm{Mg} \cdot \mathrm{ha}^{-1} ; \%\right)$ & & Mean $\pm \mathrm{Std}\left(\mathrm{Mg} \cdot \mathrm{ha}^{-1}\right)$ & $\mathrm{SE}\left(\mathrm{Mg} \cdot \mathrm{ha}^{-1} ; \%\right)$ \\
\hline OGF & 74.15 & $320.13 \pm 31.56$ & $3.69(1.15)$ & & $322.79 \pm 38.87$ & $4.35(1.34)$ \\
ODF & 32.42 & $323.72 \pm 32.51$ & $7.47(2.30)$ & & $316.52 \pm 32.82$ & $8.19(2.59)$ \\
YCF & 15.92 & $48.97 \pm 22.91$ & $15.29(31.22)$ & & $40.79 \pm 19.88$ & $17.97(44.0)$ \\
SAV & 51.69 & $12.68 \pm 20.74$ & $4.46(30.17)$ & & $14.94 \pm 22.60$ & $5.26(35.2)$ \\
Entire study area & 5044 & $223.01 \pm 121.43$ & $3.86(1.73)$ & & $220.4 \pm 120.77$ & $4.16(1.89)$ \\
\hline \hline
\end{tabular}

Std: standard deviation and SE: standard error (uncertainty).
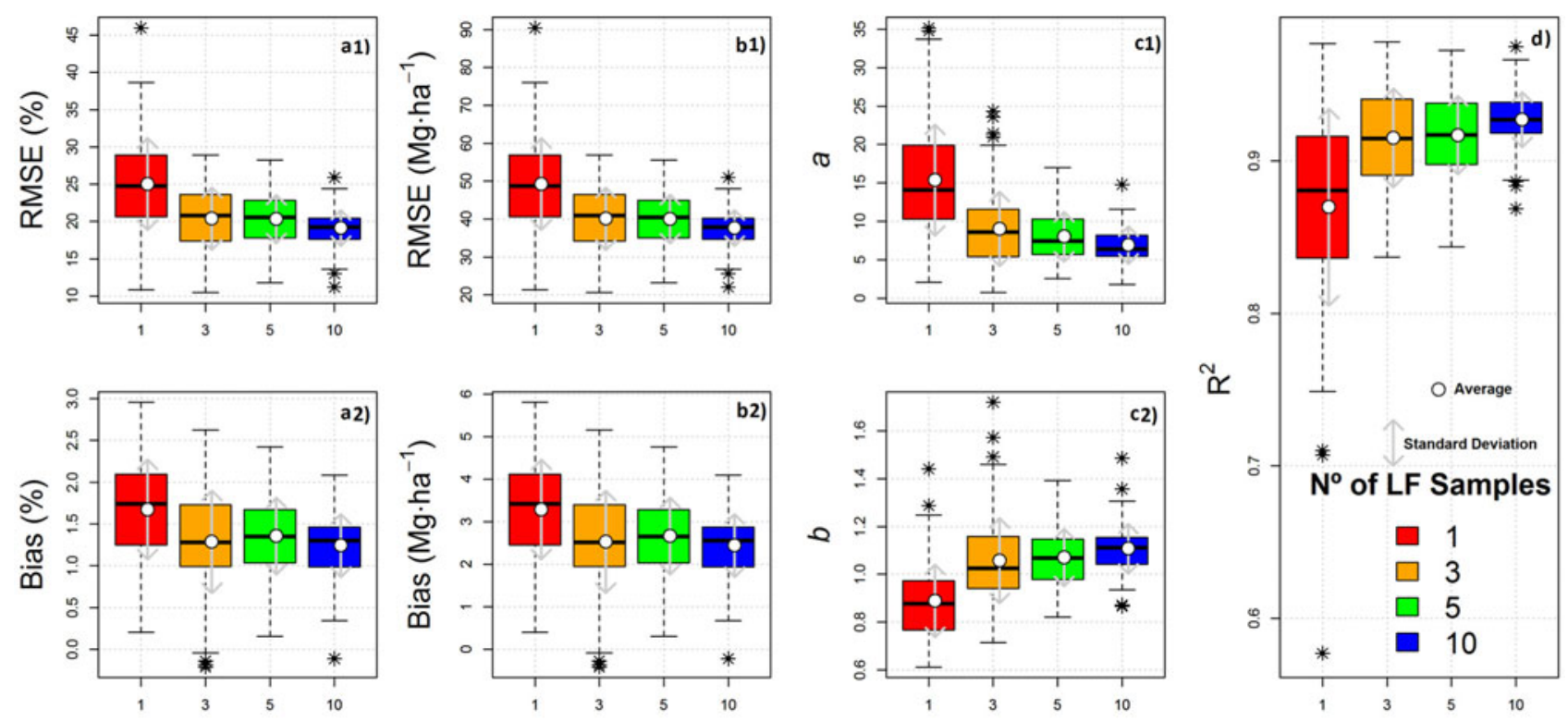

Number of large footprint Lidar samples

Fig. 9. LF simulations for AGB modeling at 1 ha. (a1) and (b1) Relative and absolute RMSE and (a2) and (b2) biases. (c1) Parameters $a$ and (c2) $b$ and (d) $R^{2}$ of the AGB models.

SF and LF lidar-derived biomass models are equivalent in performance based on Table I, but different in coefficients and if used interchangeably to predict forest AGB over the landscapes can introduce larger random or systematic errors. However, individually they provide similar mean biomass density and similar uncertainty over the study area. Results shown in Table II also suggest that the difference between the two approaches is within the margin of error in AGB estimation for each lidar approach [14], [54]. Those results also suggest that models developed with SF lidar data at landscape scale ( $\geq 1$ ha) may be used for LF lidar data as long as equivalent height metrics between the two sensors are identified (e.g., mean top canopy height).

\section{Impacts of LF Lidar Sample Size on AGB Estimation}

Reduced sample size resulted in increased RMSE and bias values, but the effect was small until only one lidar footprint was selected [see Fig. 9(a1), (a2) and (b1), (b2)]. The variability of $R^{2}$ and parameters $a$ and $b$ of the AGB models increased slightly in reduced sample sizes [see Fig. 9(c1), (c2), and (d)]. The results suggest that a minimum of three samples can potentially provide an unbiased estimate of AGB of a 1-ha area.

GEDI lidar is expected to provide global (between $\pm 51^{\circ}$ latitude) estimates of forest height structure at different spatial sampling schemas [68] such that unbiased forest biomass estimates are provided at $1-\mathrm{km}^{2}$ (100 ha) resolution. However, by clustering the samples along tracks, there is a strong probability of having a minimum of three footprints within a 1-ha area. Building on the spatial distribution of a large number of 1-ha biomass values, further work involving geostatistical modeling or machine learning approaches [69] might help increase the spatial resolution of GEDI final products from 100 to 1 ha.

\section{CONCLUSION}

In this paper, we performed a comparison of SF and LF lidar measurements of ground and forest structure, including AGB, across an AGB transition zone in central Gabon. We showed that in the dense and complex tropical forests of Central Gabon, the LF lidar measurements are equivalent to SF lidar measurements in characterizing ground elevation and maximum 
forest height. In addition, comparison of gridded LF lidar height with ground plots showed that an unbiased estimate of AGB at 1 ha can be achieved with a sufficient number of large footprints $(n \geq 3)$. The approach and results from this study can serve as a methodological basis for examining GEDI performance for estimating and mapping tropical forest structure and biomass. In addition, our results demonstrate that SF lidar measurements can be readily used for both calibration and validation of LF lidar measurements of structure and biomass over different tropical forest structures.

\section{ACKNOWLEDGMENT}

This research was performed at the Jet Propulsion Laboratory, California Institute of Technology under a funding from NASA for the AfriSAR campaign and science products. LVIS lidar and forest inventory data were acquired with support from NASA and ESA during the AfriSAR program. The small footprint lidar data acquisition was supported by funding from the US SilvaCarbon program. The authors thank B. Blair, M. Hofton, S. Hancock, and L. Duncanson at NASA Goddard Space Flight Center for their contribution by providing LVIS data.

\section{REFERENCES}

[1] M. Maltamo, N. Erik, and J. Vauhkonen, Forestry Applications of Airborne Laser Scanning: Concepts and Case Studies-Managing Forest Ecosystems, 1st ed. New Delhi, India: Delhi Book Store, 2014, pp. 01-464.

[2] C. A. Silva et al., "A principal component approach for predicting the stem volume in eucalyptus plantations in Brazil using airborne LiDAR data," Forestry, vol. 89, no. 4, pp. 422-433, Aug. 2016, doi: 10.1093/forestry/cpw016.

[3] H. Guan, J. Li, J. Yu, and L. Zhong, "DEM generation from lidar data in wooded mountain areas by cross-section plane analysis," Int. J. Remote Sens., vol. 35, no. 3, pp. 927-948, Jan. 2014, doi: 10.1080/01431161.2013.873833.

[4] R. McRoberts, Q. Chen, B. Walters, and D. Kaisershot, "The effects of global positioning system receiver accuracy on airborne laser scanningassisted estimates of aboveground biomass," Remote Sens. Environ., vol. 207, pp. 42-49, Mar. 2018, doi: 10.1016/j.rse.2017.09.036.

[5] R. McRoberts, Q. Chen, B. Walters, and D. Gormanson, "The shelflife of airborne laser scanning data for enhancing forest inventory inferences," Remote Sens. Environ., vol. 206, pp. 254-259, Mar. 2018, doi: 10.1016/j.rse.2017.12.017.

[6] M. García, D. Riaño, E. Chuvieco, and F. Danson, "Estimating biomass carbon stocks for a mediterranean forest in central Spain using LiDAR height and intensity data," Remote Sens. Environ., vol. 114, no. 4, pp. 816830, Apr. 2010, doi: 10.1016/j.rse.2009.11.021.

[7] A. T. Hudak, E. K. Strand, and L. A. Vierling, "Quantifying aboveground forest carbon pools and fluxes from repeat LiDAR surveys," Remote Sens Environ., vol. 123, pp. 25-40, Aug. 2012, doi: 10.1016/j.rse.2012.02.023.

[8] C. Silva et al., "Impacts of airborne lidar pulse density on estimating biomass stocks and changes in a selectively logged tropical forest," Remote Sens., vol. 9, no. 10, pp. 1068-1087, Oct. 2017, doi: 10.3390/rs9101068.

[9] A. Ferraz et al., "Airborne lidar estimation of aboveground forest biomass in the absence of field inventory," Remote Sens., vol. 8, no. 8, pp. 653-671, Aug. 2016, doi: 10.3390/rs8080653.

[10] E. Næsset, "Estimating timber volume of forest stands using airborne laser scanner data," Remote Sens. Environ., vol. 61, no. 2, pp. 246-253, Aug. 1997, doi: 10.1016/s0034-4257(97)00041-2.

[11] E. Næsset, "Predicting forest stand characteristics with airborne scanning laser using a practical two-stage procedure and field data," Remote Sens. Environ., vol. 80, no. 1, pp. 88-99, Apr. 2002, doi: 10.1016/S0034-4257(01)00290-5.

[12] E. Næsset and T. Økland, "Estimating tree height and tree crown properties using airborne scanning laser in a boreal nature reserve," Remote Sens. Environ., vol. 79, no. 1, pp. 105-115, Jan. 2002, doi: $10.1016 / \mathrm{S} 0034-4257(01) 00243-7$.
[13] R. Nelson et al., "Lidar sampling-Using an airborne profiler to estimate forest biomass in hedmark county, norway," Remote Sens. Environ., vol. 123, pp. 563-578, Aug. 2012, doi: 10.1016/J.RSE.2011.10.036.

[14] J. B. Drake, R. O. Dubayah, R. G. Knox, D. B. Clark, and J. B. Blair, "Sensitivity of large-footprint lidar to canopy structure and biomass in a neotropical rainforest," Remote Sens. Environ., vol. 81, nos. 2/3, pp. 378392, Aug. 2002, doi: 10.1016/s0034-4257(02)00013-5.

[15] M. L. Clark, D. B. Clark, and D. A. Roberts, "Small-footprint lidar estimation of sub-canopy elevation and tree height in a tropical rainforest landscape," Remote Sens. Environ., vol. 91, no. 1, pp. 68-89, May 2004, doi: 10.1016/j.rse.2004.02.008.

[16] J. Mascaro, G. P. Asner, H. C. Muller-Landau, M. van Breugel, J. Hall, and K. Dahlin, "Controls over aboveground forest carbon density on Barro Colorado Island, Panama," Biogeosciences, vol. 8, pp. 1615-1629, Jun. 2011, doi: 10.5194/bg-8-1615-2011.

[17] S. S. Saatchi et al., "Benchmark map of forest carbon stocks in tropical regions across three continents," Proc. Nat. Acad. Sci. USA, vol. 108, no. 24, pp. 9899-9904, Jun. 2011, doi: 10.1073/pnas.1019576108.

[18] C. A. Silva et al., "Impacts of airborne LiDAR pulse density on estimating biomass stocks and changes in a selectively logged tropical forest," Remote Sens., vol. 9, no. 10, pp. 1068-1087, Oct. 2017, doi: 10.3390/rs9101068.

[19] D. Lu et al., "Aboveground forest biomass estimation with landsat and LiDAR data and uncertainty analysis of the estimates," Int. J. Forestry Res., vol. 2012, pp. 1-16, Jan. 2012, doi: 10.1155/2012/436537.

[20] R. O. Dubayah and J. B. Drake, "Lidar remote sensing for forestry," $J$. Forestry, vol. 98, no. 6, pp. 44-46, Jun. 2000.

[21] M. A. Lefsky, W. B. Cohen, G. G. Parker, and D. J. Harding, "Lidar remote sensing for ecosystem studies," Bioscience, vol. 52, no. 1, pp. 1930, Jan. 2002.

[22] W. Qi and R. O. Dubayah, "Combining Tandem-X InSAR and simulated GEDI lidar observations for forest structure mapping," Remote Sens. Environ., vol. 187, no. 15, pp. 253-266, Dec. 2016, doi: 10.1016/j.rse.2016.10.018.

[23] M. A. Lefsky, "A global forest canopy height map from the moderate resolution imaging spectroradiometer and the geoscience laser altimeter system," Geophys. Res. Lett., vol. 37, no. 15, pp. 1-5, Aug. 2010, doi: 10.1029/2010GL043622.

[24] J. B. Drake et al., "Estimation of tropical forest structural characteristics, using large-footprint lidar," Remote Sens. Environ., vol. 79, nos. 2/3, pp. 305-309, Feb. 2002, doi: 10.1016/S0034-4257(01)00281.

[25] G. P. Asner and J. Mascaro, "Mapping tropical forest carbon: Calibrating plot estimates to a simple LiDAR metric," Remote Sens. Environ., vol. 140, pp. 614-624, Jan. 2014, doi: 10.1016/j.rse.2013.09.023.

[26] J. B. Blair and M. A. Hofton, "Modeling laser altimeter return waveforms over complex vegetation using high-resolution elevation data," Geophys. Res. Lett., vol. 26, no. 16, pp. 2509-2512, Aug. 1999, doi: 10.1029/1999GL010484.

[27] S. C. Popescu, K. Zhao, A. Neuenschwander, and C. Lin, "Satellite lidar vs. small footprint airborne lidar: Comparing the accuracy of aboveground biomass estimates and forest structure metrics at footprint level," Remote Sens. Environ., vol. 115, no. 11, pp. 2796-2797, Nov. 2011, doi: 10.1016/j.rse.2011.01.026.

[28] V. Meyer et al., "Detecting tropical forest biomass dynamics from repeated airborne lidar measurements," Biogeosciences, vol. 10, Aug. 2013, doi: 10.5194/bg-10-5421-2013.

[29] G. A. Fricker, S. S. Saatchi, V. Meyer, T. W. Gillespie, and Y. Sheng, "Application of semi-automated filter to improve waveform lidar subcanopy elevation model," Remote Sens., vol. 4, no. 6, pp. 1494-1518, May 2012, doi: 10.3390/rs4061494.

[30] T. LeToan et al., "The BIOMASS mission: Mapping global forest biomass to better understand the terrestrial carbon cycle," Remote Sens. Environ., vol. 115, no. 11, pp. 2850-2860, Nov. 2011, doi: 10.1016/J.RSE.2011.03.020.

[31] S. Saatchi, M. Marlier, R. Chazdon, D. Clark, and A. Russell, "Impact of spatial variability of tropical forest structure on radar estimation of aboveground biomass," Remote Sens. Environ., vol. 115, no. 11, pp. 28362849, Nov. 2011, doi: 10.1016/j.rse.2010.07.015.

[32] F. White, The Vegetation of Africa: A Descriptive Memoir to Accompany the Unesco/AETFAT/UNESCO Vegetation Map of Africa. Jarnac, France: Courvoisier S.A., 1983, pp. 1-325

[33] L. White and K. Abernethy, Guide de la Végétation de la Réserve de la Lopé, 2nd ed. Libreville, Gabon: ECOFAC, 1997, pp. 1-224.

[34] J. Maley, "The African rain forest: Main characteristics of changes in vegetation and climate from the Upper Cretaceous to the Quaternary," Proc. Roy. Soc. Edinburgh, vol. 104, pp. 31-73, 1996. 
[35] A. Ngomanda et al., "Western equatorial African forest-savanna mosaics: A legacy of late Holocene climatic change?" Clim. Past, vol. 5, pp. 647659, Oct 2009, doi: 10.5194/cp-5-647-2009.

[36] S. Blake, S. L. Deem, E. Mossimbo, F. Maisels, and P. Walsh, "Forest elephants: Tree planters of the Congo," Biotropica, vol. 41, no. 4, pp. 459468, Jan. 2009, doi: 10.1111/j.1744-7429.2009.00512.x.

[37] A. Cuni-Sanchez et al., "African Savanna-Forest Boundary Dynamics: A 20-year study," PLoS One, vol. 11, no. 6, pp. 1-23, Jun. 2016, doi: 10.1371/ journal.pone.0156934.

[38] G. Lopez-Gonzalez, S. L. Lewis, M. Burkitt, and O. L. Phillips, "ForestPlots.net: A web application and research tool to manage and analyses tropical forest plot data," J. Vegetation Sci., vol 22, pp. 610-613, Aug. 2011, doi: 10.1111/j.1654-1103.2011.01312.x.

[39] G. Lopez-Gonzalez, S. L. Lewis, M. Burkitt, T. R. Bakerand, and O. L. Phillips, ForestPlots.net Database 2009, Nov. 15, 2016. [Online]. Available: www.forestplots.net

[40] S. L. Lewis et al., "Aboveground biomass and structure of 260 African tropical forests," Philos. Trans. Roy. Soc. B, vol. 368, pp. 1-14, Jul. 2013 , doi. 10.1098/rstb.2012.0295

[41] J. Chave, D. A. Coomes, S. Jansen, S. L. Lewis, N. G. Swenson, and A. E. Zanne, "Towards a worldwide wood economics spectrum," Ecol. Lett., vol. 12, no. 4, pp. 351-366, 2009. [Online]. Available: https://doi.org/10.1111/j.1461-0248.2009.01285.x

[42] A. E. Zanne et al., Data from: Towards a Worldwide Wood Economics Spectrum, Dryad Digital Repository, 2009. [Online]. Available: https://doi.org/10.5061/dryad.234

[43] J. Chave et al., "Improved allometric models to estimate the aboveground biomass of tropical trees," Global Change Biol., vol. 20, no. 10, pp. 3177 3190, Oct. 2014, doi: 10.1111/gcb. 12629.

[44] P. Axelsson, "DEM generation from laser scanner data using adaptive TIN models," in International Archives of Photogrammetry and Remote Sensing. Deflt, The Netherlands: ISPRS, 2000, ch. XXXIII, pp. 110-117.

[45] J. Blair, D. Rabine, and M. Hofton, "The laser vegetation imaging sensor: A medium-altitude, digitisation-only, airborne laser altimeter for mapping vegetation and topography," ISPRS J. Photogramm. Remote Sens., vol. 54, nos. 2/3, pp. 115-122, Jul. 1999, doi: 10.1016/s0924-2716(99)00002-7.

[46] R. McGaughey, FUSION/LDV: Software for LIDAR Data Analysis and Visualization 2015, Nov. 15, 2017. [Online]. Available: http://forsys.cfr.washington.edu/fusion/fusionlatest.html

[47] M. Isenburg, LasTools-Efficient Tools for LiDAR Processing, Version 1.01.3, Nov. 15, 2017. [Online]. Available: http://lastools.org

[48] R Core Team, A Language and Environment for Statistical Computing. Vienna, Austria: R Found. Statist. Comput., vol. 2017, Nov. 15, 2017. [Online]. Available: https://www.R-project.org/

[49] Math. Graphs. Programming, MATLAB, Nov. 15, 2017. [Online]. Available: https://uk.mathworks.com/products/matlab.html

[50] M. Hofton and J. Blair, "Laser altimeter return pulse correlation: A method for detecting surface topographic change," J. Geodyn., vol. 34, nos. 3/4, pp. 477-489, Nov. 2002, doi: 10.1016/S0264-3707(02)00043-1.

[51] P. Hyde et al., "Mapping forest structure for wildlife habitat analysis using waveform lidar: Validation of montane ecosystems," Remote Sens. Environ., vol. 96, nos. 3/4, pp. 427-437, Jun. 2005, doi: 10.1016/j.rse.2005.03.005.

[52] A. Swatantran, R. Dubayah, D. Roberts, M. Hofton, and J. B. Blair, "Mapping biomass and stress in the Sierra Nevada using lidar and hyperspectral data fusion," Remote Sens. Environ., vol. 115, no. 11, pp. 2917-2930, Nov. 2011, doi: 10.1016/j.rse.2010.08.027.

[53] J. B. Blair, M. A. Hofton, and D. L. Rabine, Processing of NASA LVIS Elevation and Canopy (LGE, LCE and $L G W$ ) Data Products, version 1.01, 2006, NASA Goddard Space Flight Center, Greenbelt, MD, USA, Nov. 12, 2017. [Online]. Available: https://lvis.gsfc.nasa.gov

[54] W. Huang et al., "Mapping biomass change after forest disturbance: Applying LiDAR footprint-derived models at key map scales," Remote Sens. Environ., vol. 134, pp. 319-332, Jul. 2013, doi: 10.1016/j.rse.2013.03.017.

[55] G. Sun, K. J. Ranson, Z. Guo, Z. Zhang, P. Montesano, and D. Kimes, "Forest biomass mapping from lidar and radar synergies," Remote Sens. Environ., vol. 115, pp. 2906-2916, Mar. 2011, doi: 10.1016/j.rse.2011.03.021.

[56] D. F. Bauer, "Constructing confidence sets using rank statistics," J. Amer. Statist. Assoc., vol. 67, no. 339, pp. 687-690, Aug. 1972

[57] A. P. Robinson, R. A. Duursma, and J. D. Marshall, "A regression-based equivalence test for model validation: Shifting the burden of proof," Tree Physiol., vol. 25, no. 7, pp. 903-913, Jul. 2005.

[58] R. E. McRoberts, "A model-based approach to estimating forest area," Remote Sens. Environ., vol. 103, no. 1, pp. 56-66, Jul. 2006, doi: 10.1016/j.rse.2006.03.005.
[59] C. R. Weisbin, W. Lincoln, and S. Saatchi, "A systems engineering approach to estimating uncertainty in above-ground biomass (AGB) derived from remote-sensing data," Syst. Eng., vol. 17, no. 3, pp. 361-373, Fall 2014.

[60] M. Garcia et al., "Quantifying biomass consumption and carbon release from the california rim fire by integrating airborne lidar and landsat OLI data," J. Geophys. Res. Biogeosci., vol. 122, pp. 340-353, Feb. 2017, doi: 10.1002/2015JG003315.

[61] C. A. Silva, C. Klauberg, S. P. C. Carvalho, A. T. Hudak, and L. C. E. Rodriguez, "Mapping aboveground carbon stocks using LiDAR data in Eucalyptus spp. plantations in the state of São Paulo, Brazil," Sci. Forestalis, vol. 42, no. 104, pp. 591-604, Dec. 2014.

[62] C. A. Silva et al., "Imputation of individual longleaf pine (Pinus palustris Mill.) Tree attributes from field and LiDAR data," Can. J Remote Sens., vol. 42 , no. 5 , pp. 554-573, Oct. 2016.

[63] C. A. Silva et al., "Combined effect of pulse density and grid cell size on predicting and mapping aboveground carbon in fast-growing Eucalyptus forest plantation using airborne LiDAR data," Carbon Balance Manage., vol. 12, no. 13, pp. 13-29, Jun. 2017.

[64] C. A. Silva et al., "Predicting stem total and assortment volumes in an industrial pinus taeda L. Forest plantation using airborne laser scanning data and random forest," Forests, vol. 8, no. 7, pp. 254-267, Jul. 2017.

[65] S. Lee, W. Ni-Meister, W. Yang, and Q. Chen, "Physically based vertical vegetation structure retrieval from ICESat data: Validation using LVIS in White Mountain National Forest, New Hampshire, USA," Remote Sens. Environ., vol. 115, no. 11, pp. 2776-2785, Nov. 2011, doi: 10.1016/j.rse.2010.08.026.

[66] M. Hofton, L. Rocchio, J. Blair, and R. Dubayah, "Validation of vegetation canopy lidar sub-canopy topography measurements for a dense tropical forest," J. Geodyn., vol. 34, nos. 3/4, pp. 491-502, Oct./Nov. 2002, doi: 10.1016/S0264-3707(02)00046-7.

[67] T. Park et al., "Application of physically-based slope correction for maximum forest canopy height estimation using waveform lidar across different footprint sizes and locations: Tests on LVIS and GLAS," Remote Sens. vol. 6, no. 7, pp. 6566-6586, Jul. 2014, doi: 10.3390/rs6076566.

[68] E. N. Stavros et al., "ISS observations offer insights into plant function," Nat. Ecol. Evol., vol. 1, no. 194, pp. 1-4, Jun. 2017, doi 10.1038/s41559-017-0194.

[69] L. Xu et al., "Spatial distribution of carbon stored in forests of the Democratic Republic of Congo," Sci. Rep., vol. 7, no. 15030, pp. 1-12, May 2017, doi: 10.1038/s41598-017-15050-z.

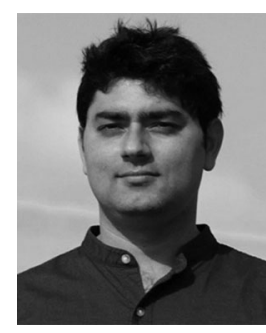

Carlos Alberto Silva received the B.S. degree in forest engineering and the M.S. degree in forest resources from the Luiz de Queiroz College of Agriculture, University of São Paulo, Piracicaba, Brazil, in 2011 and 2013, respectively, and the Ph.D. degree in natural resources from the University of Idaho, Moscow, ID, USA, in 2018.

His current research interest includes using lidar remote sensing technology for predicting and mapping forest attributes across natural and plantation forests.

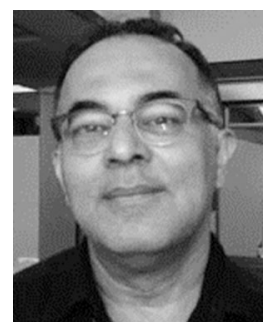

Sassan Saatchi received the Ph.D. degree with concentration in electrophysics and applied mathematics from George Washington University, Washington, DC, USA, in 1988.

$\mathrm{He}$ is currently a Senior Scientist with the Jet Propulsion Laboratory, California Institute of Technology, Pasadena, CA, USA, and an Adjunct Professor with the Center for Tropical Research, Institute of Environment, University of California at Los Angeles, Los Angeles, CA. His current research interests include land cover classification, biomass and soil moisture estimation in boreal forests, land use and land cover change, fores structure and carbon stock in tropical forests, applications of remote sensing in biodiversity and conservation. 


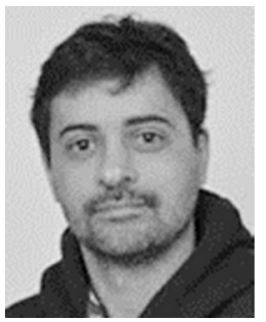

Mariano Garcia received the Ph.D. degree in geographical information technologies from the University of Alcalá, Madrid, Spain, in 2011.

During this research, he was a Marie Curie Research Associate with the University of Leicester, England. He is currently an Assistant Professor with the University of Alcalá. His research interests include the development of methods to derive improved information on 3-D forest structure from passive and active (Lidar and SAR) remote sensing data. He is particularly interested in the role of forest fires in the structure and functioning of different terrestrial ecosystems for which fires are a major disturbance factor.

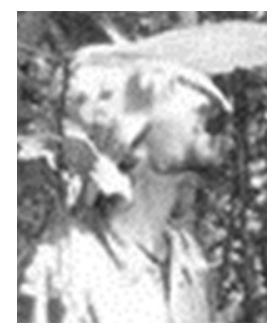

Nicolas Labrière received the Ph.D. degree in environmental science from Agro ParisTech, Paris, France.

He is a Postdoctoral Research Associate funded by CNES. During his Ph.D. research, he has extensively worked in the Bornean forests, with Yves Laumonier and Bruno Locatelli. Shortly thereafter, he was hired in Simon Lewis Lab, UCL, to lead a field survey at the Lopé field station in Gabon, as part of the European Space Agency funded campaign AfriSAR. $\mathrm{He}$ is exploring the capacity of the TROLL individual-based model to assimilate remote sensing and ground data from the AfriSAR campaign. He will also contribute to the global effort of collecting in situ biomass data for the Forest Observation System, in particular with the TmFO network.

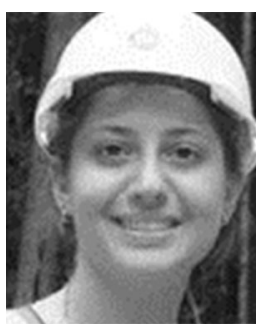

Carine Klauberg received the Ph.D. degree in forest resources from the Luiz de Queiroz College of Agriculture, University of São Paulo, Piracicaba, Brazil, in 2014.

She is currently a Visitor Scientist with the Rocky Mountain Research Station, USDA Forest Service, Moscow, ID, USA. The main goal of her research is to afford forestry managers with information and tools that will enable them to become better stewards to sustain or restore healthy and sustainable forestry environments. She works at the interface of three disciplines: forest management, remote sensing, and modeling. Her research looks into various forest management feedback mechanisms, which integrate botany, phytosociology, forest ecology and inventory, geostatistics, remote sensing, wildfire, and nontimber forest products into a single system-forestry.

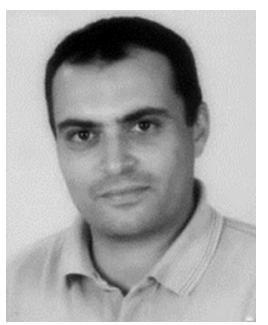

António Ferraz was born in Antas de Penedono, Portugal. He received the M.S. degree in geomatics engineering from the Universidade de Coimbra, Coimbra, Portugal, in 2007, and the Ph.D. degree in geophysics from the Institute de Physique du Globe de Paris, Paris, France, in 2012.

From November 2007 to January 2014, he was with the French National Institute for Geographic Information and Forestry, Paris. Since May 2014, he has been with the NASA Postdoctoral Program, Jet Propulsion Laboratory, California Institute of Technology, Pasadena, CA, USA. His main research interests include remote sensing of vegetation, optical image and 3-D point cloud processing, direct retrieval of forest variables using airborne laser scanning systems, forest 3-D modeling, and carbon and biomass estimation over tropical environments.

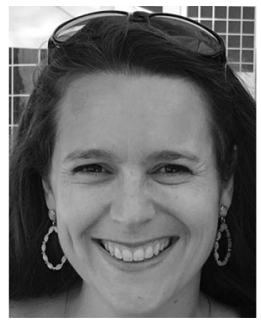

Victoria Meyer received the Ph.D. degree in environment science from the University of Paul Sabatier (Toulouse III), Toulouse, France, in 2017.

She is current a Postdoctoral Research Associate with the Jet Propulsion Laboratory, California Institute of Technology, Pasadena, CA, USA. She is working on the potential of lidar data to recover biomass and forest structure information in old-growth tropical forests.

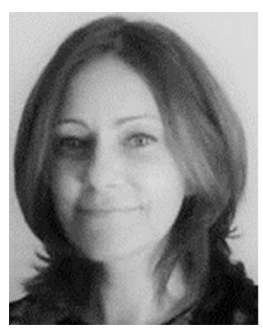

Kathryn J. Jeffery received the Ph.D. degree from Cardiff University, Cardiff, U.K., in 2003, on the sociogenetics of the gorilla community in Gabon, adopting a forensic approach to genetically track wild apes following a period working for the Forensic Science Service in London.

She went on to direct the Wildlife Conservation Society's Training Centre (CEDAMM) in Lopé National Park for two years, where she developed and ran a number of training courses for Gabonese undergraduates. She then directed the SEGC research station for four years and oversaw a multidisciplinary research program focusing on carbon storage and climate change, great ape health and genetics, invasive species ecology, and fire ecology. She is currently a Scientific Advisor for the National Parks Agency in Gabon (ANPN) and an Associate Researcher for the National Centre for Research in Science and Technology (CENAREST), Libreville, Gabon. She is a Postdoctoral Researcher with the University of Stirling, Stirling, U.K.

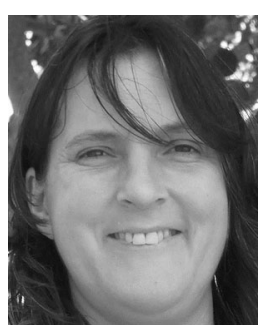

Katharine Abernethy received the Ph.D. degree from the University of Edinburgh, Edinburgh, U.K., in 1994, on the introduction of Sika deer to Scotland.

She went to Gabon in 1993 as a Postdoctoral Researcher and became the Director of the Station d'Etudes des Gorilles et Chimpanzés, Lopé National Park, in 2000, a post she held until 2007. She spent several years studying ape ecology before pioneering research into the ecology of mandrills and supervising several $\mathrm{PhDs}$ on large mammal ecology and conservation. She then went on to establish many of the Wildlife Conservation Society's activities in Lopé including the CEDAMM training centre, a community outreach project, an Eco-museum, and a mandrill tourism project. She has influenced environmental policy through several highprofile projects, including The National Strategy for Bushmeat Management in Gabon. She is also a successful botanical artist and her work is widely published.

Dr. Abernethy is currently a Senior Research Fellow with the University of Stirling, Stirling, U.K., a Member of the IUCN Species Survival Commission, and an Associate Researcher for the National Centre for Research in Science and Technology in Gabon, Libreville, Gabon.

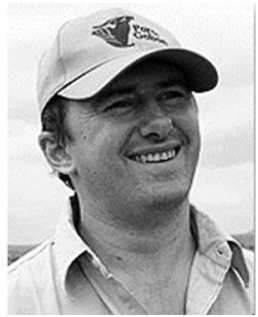

Lee White received the Ph.D. degree on the effects of vegetation history and logging on rainforest mammals from the University of Edinburgh, Edinburgh, U.K., in 1992 .

He went on to a Postdoctoral Researcher on vegetation history in Lope, setting up botanical plots to describe and monitor change in the vegetation of the region, before founding the WCS-Gabon program, writing several technical books on African Forest conservation, developing training program for national and international students and playing a key role in the creation of Gabon's national parks. He directed the Wildlife Conservation Society Program in Gabon until 2007 and in 2009 became the Head of the National Parks Agency in Gabon (ANPN), responsible for a network of 13 National Parks.

Dr. White is the Technical Director of the Gabonese Government's Climate Change Task Force. He is an Honorary Research Fellow with the University of Stirling and is a prominent conservationist in Africa. 


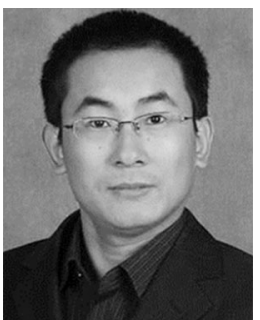

Kaiguang Zhao received the Ph.D. degree in forestry from Texas A\&M University, College Station, TX, USA, in 2008.

$\mathrm{He}$ is currently an Assistant Professor of environmental modeling and spatial analysis with Ohio State University, Columbus, OH, USA. His research interests include mapping, monitoring, modeling, and managing terrestrial environments across scales, especially in the context of global environmental changes.

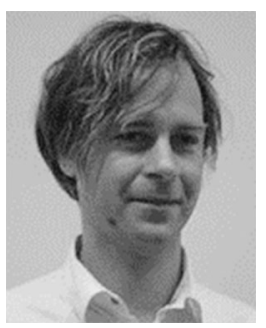

Simon L. Lewis received the Ph.D. degree in tropical forest ecology from the University of Cambridge, Cambridge, U.K., in 1998.

$\mathrm{He}$ is a Professor of global change science with University College London, London, U.K., as a halftime position. He holds an equivalent position with the University of Leeds, Leeds, U.K. His primary research interest includes how humans are changing the earth as a system.

Dr. Lewis was a Royal Society University Research Fellow (2004-2013), and was a recipient of Philip Leverhulme Prize recognizing the international impact of his research in 2011.

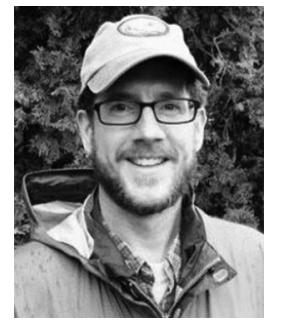

Andrew T. Hudak received the Ph.D. degree in environmental, population, and organismic biology from the University of Colorado, Denver, CO, USA, in 1999.

$\mathrm{He}$ is a Research Forester with the Rocky Mountain Research Station, USDA Forest Service, Moscow, ID, USA. His research interests include landscape, vegetation, and fire ecology; remote sensing of vegetation patterns and processes; forest and rangeland ecology and management; empirical modeling of spatially explicit ecological data. 